\title{
Dasein, personeidad, intersubjetividad y persona-núcleo (III). La estructura transcendental discursiva después de Heidegger, en Zubiri, Apel y Polo
}

\author{
Dasein, personality, inter-subjectivity and nucleus-person (III). \\ The discursive transcendental structure after Heidegger, \\ in Zubiri, Apel and Polo
}

Carlos Ortiz de Landázuri

Universidad de Navarra

cortiz@unav.es

\section{Resumen}

Se prolongan las anteriores consideraciones acerca del Dasein, la personeidad, la intersubjetividad y la persona núcleo, en Heidegger, Zubiri, Apel y Polo, respectivamente. Se analiza, en concreto, la estructura transcendental discursiva que hace posible sus respectivas relaciones con el "ser de los entes", con el mundo, con el resto de los entes y con sus demás semejantes, incluido uno mismo.

Palabras clave: Deliberación, responsabilidad, situaciones límite, discurso racional.

\section{Abstract}

The previous considerations on Dasein, personeity, intersubjectivity and the nucleus-person are prolonged, in Heidegger, Zubiri, Apel and Polo, respectively. It analyzes in particular the deliberative transcendental structure that makes possible their respective relations with the "being of the beings", with the world, with the rest of the beings and with their fellow beings, including oneself.

Keywords: Deliberation, responsibility, limit situations, rational discourse. 


\section{1.- La estructura transcendental discursiva de la persona, después de Heidegger}

Una vez comprobado el sentido transcendental especulativo que puede alcanzar la persona en las relaciones que mantiene respecto de los entes, el mundo, o sus propios semejantes, queda aún un segundo problema por abordar, ${ }^{1}$ a saber: comprobar cómo Heidegger en Ser y tiempo - SyT ${ }^{2}-(1927)$ concibió al Dasein como un ente arrojado al mundo, entre las cosas y sus propios semejantes, al que, además, se le exige que sea consecuente con esta situación única en la que se encuentra, a pesar de no haber tomado parte en esta decisión. Especialmente cuando el primer Heidegger consideró al Dasein en Ser y tiempo como un ser arrojado al mundo, sobre el que recae la pesada carga de tener que sobrellevar a la fuerza un dominio que ejerce sobre los demás entes que claramente le supera. Con la circunstancia añadida de que tampoco puede dejar de asumir deliberadamente esta gravosa responsabilidad, de la que depende la supervivencia de su propio ser y de sus semejantes. Máxime, cuando se encuentra en la imposibilidad absoluta de poder superar la diferencia óntico-ontológica que le hubiera permitido acceder a aquel "ser de los entes" desde el que hubiera sido posible dirimir el sentido preciso que en este proyecto le corresponde a cada ente en particular, incluido el propio mundo o el propio Dasein. Sólo así hubiera sido posible asumir una obligatoriedad proporcionada ante los demás "entes", a pesar de sentirse cada vez más incapacitado para estar a la altura de la responsabilidad que se le exige. ${ }^{3}$

De todos modos, siempre le queda al Dasein en Heidegger la capacidad de relacionarse con el resto de los entes en general y con los demás Dasein en particular, dado el poder de deliberación mancomunada que, por recurso

1 Ortiz de Landézuri, C., “Dasein, personeidad, intersubjetividad y persona-núcleo (II). La estructura transcendental intelectiva después de Heidegger, en Zubiri, Apel y Polo", Metafísica y persona, núm. 15, 2016, pp. 41-100.

2 Heidegger, M., Ser y tiempo, Madrid: Trotta, 2003.

3 A este respecto, afirma Heidegger: "Considerada en su contenido, la fenomenología es la ciencia del ser del ente-ontología. [...] De la investigación misma se desprenderá que el sentido de la descripción fenomenológica en cuanto método es el de la interpretación (Auslegung). El 'logos' de la fenomenología del Dasein tiene el carácter de "ermeneiein", por cual le son anunciados que la comprensión del ser que es propia del Dasein mismo el auténtico sentido del ser y de las estructuras fundamentales de su propio ser. La fenomenología del Dasein es hermenéutica, en la significación originaria de la palabra, significación en la que se designa el papel de la interpretación, [así como] en el sentido de la elaboración de las condiciones de posibilidad de toda investigación ontológica; [es decir] el sentido de una analítica de la existencialidad de la existencia. En cuanto esta analítica elabora antológicamente la historicidad del Dasein como condición óntica de posibilidad del ser histórico, ella sirve, en seguida, de terreno de arraigo para aquello que sólo derivadamente puede ser llamado 'hermenéutica': la metodología de las ciencias históricas del espíritu". HeIDEgGer, SyT, p. 58. cf. Weber, K. (Hg.); Sucht, Hamburg: Argument, 2011. 
DASEIN, PERSONEIDAD, INTERSUbJETIVIDAD Y PERSONA-NÚCleO (III). LA ESTRUCTURA

transcendental discursiva después de Heidegger, en Zubiri, Apel y Polo

al lenguaje, también se le otorga a este respecto. En este sentido, el primer Heidegger habría acabado otorgando al Dasein una estructura transcendental discursiva capaz de afrontar este tipo de situaciones, a pesar de tampoco saber el quién ni el porqué de este tipo de responsabilidades que ahora se le arrojan sobre su exclusivo ámbito de decisión. En cualquier caso, ya lo haga con agrado o con aversión, tampoco puede dejar el Dasein de eludir esta pesada carga que le ha sido impuesta, teniéndola que asumir necesariamente, aunque le genere angustia y desesperación; sin poder saber el acierto o desacierto del alcance transcendental de las decisiones tomadas. En este sentido, en Heidegger tampoco habría podido eludir, en Ser y tiempo, que esta misma relación con los demás Dasein se acabara viendo obligada a solventar unas relaciones de solidaridad y de mutua ayuda, cada vez más desorbitadas y carentes de sentido. Con el agravante de sólo poder hacer aportaciones que resultan cada vez más inútiles y contraproducentes, sin tampoco poder estar a la altura de las exigencias que ahora se le piden. Por eso el último Heidegger acabaría concibiendo al Dasein como si se tratara un sujeto postmoderno desestructurado, que debe abandonar definitivamente este tipo de pretensiones utópicas absolutamente ilusorias, teniendo que asumir la infradotación y la debilidad congénita de este tipo de estructuras discursivas transcendentales. ${ }^{4}$

Por su parte, Zubiri, Apel y Polo trataron de prolongar y de desactivar la actitud tan desesperada fomentada por Heidegger. Especialmente, su pretensión de fomentar actitudes tan derrotistas, aunque en cada caso se tuviera que defender en su lugar una estructura transcendental discursiva muy diferente. Zubiri, en Sobre la esencia -SE ${ }^{5}$-, de 1963, llega a calificar de absurda la propuesta heideggeriana, aunque se reconozca como en una situación límite, tampoco la personeidad dispone de los medios necesarios para poder ejercer una responsabilidad transcendental proporcionada al alcance que se le exige. Por su parte Apel, en un conjunto de artículos de 1963 y 1965, recogidos en Transformación de la filosofía - $\mathrm{TF}^{6}-$, de 1972, considerará excesivamente débi-

${ }_{4}$ A este respecto, afirma Heidegger: “Una analítica del Dasein debe constituir, pues, la primera exigencia que plantea la pregunta por el ser. Pero entonces el problema de la obtención y el aseguramiento de la forma de acceso al Dasein se torna plenamente candente. Dicho de manera negativa: no se debe aplicar a este ente de un modo dogmático y constructivo una idea cualquiera de ser y realidad, por muy 'obvia' que ella sea; ni se deben imponer al Dasein, sin previo examen ontológico, 'categorías' bosquejadas a partir de tal idea. El modo de acceso e interpretación debe ser escogido, por el contrario, de tal manera que este ente se pueda mostrar a sí mismo y desde sí mismo. Y esto quiere decir que el ente deberá mostrarse tal y como es inmediata y regularmente, en su cotidianeidad media [...] sacando estructuras esenciales, que se mantengan en el modo de ser del Dasein fáctico como determinantes de su ser". Heidegger, M.; SyT, pp. 37-38 p. Cf. Melich, J-C., La prosa de la vida. Fragmentos filosóficos II, Barcelona: Fragmenta, 2016, 118 pp.

5 Zubiri, X., Sobre la esencia, Madrid: Sociedad de Estudios y Publicaciones, 1962.

6 Apel, K-O., Transformation der Philsophie,T I-II, Frankfurt: Suhrkamp, 1972; Transformación de la filosofía, T I-II, Madrid: Taurus, 1985. 
les los motivos que ahora se alegan para eludir un desarrollo más completo de la estructura transcendental discursiva, que ahora se asigna a la intersubjetividad o co-subjetividad existente entre los distintos participantes en un discurso racional, cuando debería bastar este motivo para que la humanidad fomentara una ayuda compartida cada vez más solidaria a la hora de tener que asumir de un modo irrenunciable este tipo de responsabilidades compartidas. Finalmente, Polo en El acceso al ser $-\mathrm{AS}^{7}-$, de 1964, también admitirá la debilidad e infradotación asignada a la estructura transcendental discursiva donde se encuentra inserta el núcleo íntimo más personal de uno mismo. A este respecto, se hará necesaria la adquisición de unos hábitos voluntarios e intelectivos capaces de otorgar a dicha estructura una creciente plenitud de sentido de orden existencial. Sólo así la persona-núcleo se podrá hacer acreedora de una dignidad entitativa en sí misma irrenunciable, siempre que a su vez demuestre una capacidad efectiva de desarrollar todas estas posibilidades que ahora se le ofrecen. ${ }^{8}$

\section{El arrojamiento del Dasein como ser en el mundo, según Heidegger}

El punto de partida de las reflexiones de Heidegger acerca del papel del Dasein en la estructura transcendental discursiva reside en un punto muy concreto, a saber: el reconocimiento de que la constatación de la singularidad óntica del Dasein como único "ser en el mundo" capaz de conocer a los demás entes. Se genera así una situación efectiva de tedio persistente, monótono y descolorido frente los demás entes, por un motivo muy sencillo: la incapacidad del Dasein de asumir una responsabilidad tan abrumadora como la que ahora se le impone. En efecto, en la misma medida que el Dasein es el único ente capaz de reconocer su peculiar situación ontológica frente a los demás entes, a los demás Dasein, e incluso frente el "ser de los entes", tampoco puede dejar de contraer una peculiar responsabilidad igualmente óntica con todos ellos. Máxime, cuando se asigna una singularidad entitativa que le sobreviene en una situación de absoluta indeterminación discursiva, sin que tampoco pueda poner nada de su parte para modificar este estado de cosas. De hecho, se debe enfrentar a unas exigencias que claramente sobrepasan con mucho las posibilidades efectivas de la estructura transcendental de la comprensión para poder llevarlas a cabo. En este sentido se ve en la necesidad de asignarse una

Polo, L., El acceso al ser, Pamplona: Eunsa, 1964.

8 Gillet, C., Reduction and Emergence in Science and Philosophy, Cambridge: Cambridge University press, 2016. 
DASEIN, PERSONEIDAD, INTERSUbJETIVIDAD Y PERSONA-NÚCleO (III). LA ESTRUCTURA transcendental discursiva después de Heidegger, en Zubiri, Apel y Polo

segunda estructura transcendental discursiva en virtud de su "ser arrojado al mundo" y de las mayores responsabilidades compartidas que, sin haberlo querido, en estos casos se contraen. ${ }^{9}$

Se localiza así una desproporción totalmente injustificada entre ambas estructuras, que generan innumerables situaciones límites sin solución posible, sin que tampoco sea nada gratificante para el Dasein abordar este tipo de conflictos. Por ello, inicialmente, la apropiación de esta nueva estructura transcendental se percibe como una carga irremediable que, a su vez, podría ser producto de un simple autoengaño deliberado, del que siempre se puede extraer una enseñanza positiva: la razón de ser última de esta situación, tan paradójica, es una simple consecuencia del consiguiente reconocimiento que el Dasein debe hacer de su ser-ahí en medio de otros entes, y, en definitiva, en medio del "mundo". Se genera así un autoengaño entre lo que el Dasein cree ser y lo que es desde un punto de vista óntico efectivamente. Al menos de este modo se pone de manifiesto "cómo uno está y cómo a uno le va", sin poderse tampoco hacer falsas ilusiones al respecto. El Dasein fomenta así un "estado de ánimo" o un temple moral de angustia absolutamente pesimista, que a su vez le permite reconocer los problemas efectivos con los que se encuentra su ser-ahí de un modo tremendamente realista. En este sentido tampoco se puede hacer la falsa ilusión de situarse "fuera" del mundo, como si no estuviera arrojado a un ahí o lugar concreto. ${ }^{10}$

Se trata de un tránsito que experimenta el Dasein entre dos situaciones discursivas aparentemente opuestas, pero en el fondo complementarias. De he-

9 A este respecto, afirma Heidegger: "Siendo fundamento, es decir, existiendo como arrojado, el Dasein queda constantemente a la zaga de sus posibilidades. Nunca existe antes de su fundamento, sino que siempre sólo desde y como él. Ser-fundamento significa, por consiguiente, no ser jamás radicalmente dueño del ser más propio. Ésta no pertenece al sentido existencial de la condición de arrojado. Siendo fundamento, es, él mismo, una nihilidad de sí mismo. [...] El carácter negativo de este "no" se determina existencialmente así: siendo sí mismo, el Dasein es el ente arrojado en cuanto el fundamento, para ser este fundamento. El Dasein no es, él mismo, el fundamento de su ser en cuanto que éste brotara de un proyectarse del propio Dasein, pero siendo sí-mismo, el Dasein es, sin embargo, el ser de ese fundamento. Éste es siempre tan sólo fundamento de un ente cuyo ser tiene que asumir el ser-fundamento". Heidegger, M, SyT, 301 p. Cf. Wagner, F. (Ed.); Was ist Text? Aspekte einer interdisziplinären Texttheorie. Basel: Schwabe, 2016.

${ }^{10}$ A este respecto, afirma Heidegger: "La indeterminación afectiva, a menudo persistente, monótona y descolorida, que no debe ser confundida con el mal humor, no sólo es una nada, sino que, por el contrario, precisamente en ella el Dasein se vuelve tedioso a sí mismo. En semejante indeterminación afectiva, el ser Ahí se ha manifestado como una carga. ¿Por qué? No se sabe. Y el Dasein no puede saber tales cosas, porque las posibilidades de apertura del conocimiento quedan demasiado cortas frente al originario abrir de los estados de ánimo, en los cuales el Dasein queda puesto en su ser en cuanto Ahí. [...\} El estado de ánimo manifiesta el modo "como uno está y como a uno le va". En este "como uno está", el temple anímico pone al ser en su "Ahí". (SyT, 153-154 pp.). Cf. Sмітн, J. E. H., The Philosopher. A History in Six Types, Princeton: Princeton University Press, 2016. 
cho, permiten el descubrimiento fáctico de los objetos a un nivel simplemente perceptivo, a la vez que permite el hallazgo de aquellas exigencias discursivas existenciales que se derivan de este mismo descubrimiento. En efecto, a un nivel especulativo se le atribuye al Dasein una situación afectiva de indiferencia irresponsable frente a todos los demás entes, por ver obligado a asumir una carga que absolutamente le supera. De este modo se ve obligado a asumir un protagonismo como "ser en el mundo", que le ofrece todo tipo de posibilidades de apertura, ya sea respecto de los entes, respecto del mundo, respecto de sí mismo, o incluso respecto del propio "ser de los entes", con las lógicas limitaciones que en cada caso se señalan. A este respecto, el Dasein dispone desde un punto de vista especulativo la denominada libertad de la indiferencia, así como del correspondiente estado de ánimo, de temple moral, de dominio o superioridad sobre todas las cosas, con una sola excepción: la incapacidad ya reconocida de poder salvar la diferencia óntico-ontológica radical última que ahora se establece entre los "entes" y el correspondiente "ser de los entes". Sin embargo, ahora se reconoce cómo este estado de ánimo de dominio, o de superioridad óntica sobre el resto de los entes, se puede transformar en una condición de arrojamiento y sumisión respecto de los demás entes. Se genera así en el Dasein un estado de ánimo de monotonía y tedio, persistente y descolorido, al sentirse arrojado a una situación inesperada, que le sobreviene sin tampoco haber hecho nada por procurarla. ${ }^{11}$

Se trata de la facticidad de la entrega a uno mismo, que le hace reconocer su peculiar situación de arrojamiento y sumisión de uno mismo frente a los demás entes o frente al propio mundo, sin poderse ya refugiar en el anonimato de concebirse como un entre igual a los demás. Se trata de la comprobación de la presencia de un ahí no meramente fáctico, sino existencial, en la medida que se comprueba el modo peculiar como cada Dasein define su posición ente los demás entes y en el mundo. Sólo así se destaca cómo el Dasein se concibe como un ente distinto a los demás, sin tampoco poder eludir las exigencias existenciales que este hecho comporta ante los demás entes y ante uno mismo. De hecho, el Dasein se concebía primero como un ser-ahí meramente óntico o incluso ontológico estrictamente especulativo, como si se tratara de un simple hecho bruto (factum brutum), para indicar así su apertura a todos los entes en

\footnotetext{
11 "El Dasein tiene, por consiguiente, en varios sentidos, una primacía sobre todo ente. En primer lugar, una primacía óntica. El Dasein está determinado en su ser por la existencia. En segundo lugar, una primacía ontológica: en virtud de su determinación por la existencia, el Dasein es 'ontológico' por sí mismo. Ahora bien, al Dasein le pertenece con igual originariedad -como constitutivo de la comprensión de la existencia- una comprensión del ser de todo ente que no tiene el modo de ser del Dasein. Por consiguiente, el Dasein tiene una tercera primacía: la de ser la condición de posibilidad óntico-ontológica de todas las ontologías. El Dasein se ha revelado, pues, como aquello que, desde el punto de vista ontológico, debe ser interrogado con prioridad a todo ente". Heidegger, SyT, 35 p. Cf. Coliva, A., The Varieties of Self-Knowledge, London: Palgrave, 2016.
} 
DASEIN, PERSONEIDAD, INTERSUbJETIVIDAD Y PERSONA-NÚCleO (III). LA ESTRUCTURA transcendental discursiva después de Heidegger, en Zubiri, Apel y Polo

general y al mundo en especial. Sin embargo, en un segundo momento, se comprueba cómo este inicial hecho bruto viene acompañado de un "qué es" existencial mediante el que se comprueba la situación concreta de arrojamiento al mundo en la que el Dasein se encuentra inserto. Además, en una situación tan límite también se hacen evidentes las exigencias existenciales concretas que le sobrevienen al Dasein precisamente por estar ahí, ocupando un lugar concreto en el mundo que es distinto a cualquier otro. No se trata, sin embargo, de una simple facticidad física, que se pueda percibir mediante un tipo de intuiciones simplemente perceptivas. Se trata más bien de una facticidad existencial que caracteriza al "qué es" de cada "ente", y cuya captación requiere una reflexión especulativa previa, sin poderse concebir como si se tratara de un simple ente o una cosa igual a las demás, que a su vez se pudiera captar mediante una mera intuición perceptiva. ${ }^{12}$

El Dasein adquiere así una condición de arrojado en el mundo, como consecuencia del papel existencial que la estructura transcendental discursiva desempeña en el conjunto de los entes. Es decir, el Dasein puede seguir adoptando una actitud meramente especulativa que le permite atribuirse la apertura y el dominio que le corresponde por el simple hecho de concebirse como un "ser en el mundo" distinto a los demás entes. Sin embargo, también puede adoptar deliberadamente el estado afectivo que le corresponde por sentirse arrojado sin previo aviso en medio de los demás entes. Pero a la vez ello mismo le acabará exigiendo adoptar una actitud más realista respecto de las exigencias existenciales absolutamente desproporcionadas que se derivan de su peculiar condición de estar-ahí, sin poderlo reducir a un hecho simplemente físico. De este modo, el Dasein se encuentra a sí mismo sin poderse reducir ya a un ente igual a los demás, sino teniéndose que concebir deliberadamente como un ente que está existencialmente afectado por los demás entes, sin poder dar ya la espalda a las exigencias ontológicas que se derivan de este enraizamiento. ${ }^{13}$

${ }^{12}$ A este respecto, afirma Heidegger: "Este carácter del ser del Dasein, oculto en su de-donde y adonde, pero claramente abierto en sí mismo, es decir, en el 'que es', es lo que llamamos la condición de arrojado ('Geworfenheit') de este ente en su Ahí: de modo que, en cuanto estar en el mundo, el Dasein en el Ahí. El término 'condición arrojado' mienta la facticidad de la entrega a sí mismo. El Facttum de 'que es y tiene que ser', abierto en la disposición afectiva del Dasein. No es aquel 'que es' que ontológico-categorialmente expresa el carácter hecho del propio estar-ahí. Este carácter sólo es accesible a la constatación que se origina en la mirada contemplativa. En cambio, 'que es' abierto a la disposición afectiva debe concebirse como determinación existencial del ente que es en la forma de 'estar-en -este-mundo'. La facticidad no es el carácter de hecho del facttum brutum de algo que está ahí, sino un carácter de ser del Dasein, asumido en la existencia, aunque, por lo pronto, reprimido. El 'que es' de la facticidad jamás puede ser hallado en una intuición". (SyT, 154 p.). Cf. Gross, S.; Tebben, N.; Williams, M. (Eds.), Meaning Without Representation. Essays on Truth, Expression, Normativity, and Naturalism, Oxford: Oxford University Press, 2015.

13 “Las ciencias son maneras de ser del Dasein en las que éste se comporta también en relación a entes que pueden ser otros que él. Ahora bien, al Dasein le pertenece esencialmente el estar en 
Por eso, la reacción del Dasein ante este tipo de situaciones límites, más que un "buscar" -como ocurría anteriormente a un nivel especulativo- es un "huir". En efecto, en lugar de tratar de descubrir nuevas posibilidades, se trata de eludir este tipo de exigencias existenciales que de un modo afectivo y también deliberativo se generan, en la medida de lo posible. En general, el Dasein trata de eludir el aspecto de carga que genera la condición de sentirse arrojado en medio del mundo. Por eso, dadas las múltiples posibilidades que se le ofrecen, prefiere iniciar un proceso de conversión o de aversión, según se esté a favor o en contra del tipo de exigencias existenciales que ahora genera el ser-ahí donde en cada caso el Dasein se encuentra. En cualquier caso, ya afronte el Dasein la situación con una disposición u otra, ya se encuentre librado de esa sensación de carga por poder afrontarla con un ánimo elevado, o, por el contrario, de aversión por generarle una presión que considera desproporcionada, lo fundamental está en un hallazgo, a saber: el descubrimiento de la estructura transcendental discursiva que se genera por el mero hecho existencial de encontrarse en medio del mundo, sin poder eludir ya las disposiciones afectivas ontológicas que este tipo de situaciones existenciales generan. ${ }^{14}$

el mundo. La comprensión del ser propia del Dasein comporta, pues, con igual originariedad, la comprensión de algo así como un 'mundo', y la comprensión del ser del ente que se hace accesible dentro del mundo. Las ontologías cuyo tema es el ente que no tiene el carácter de ser del Dasein están, por ende, fundadas y motivadas en la estructura óntica del Dasein mismo, que lleva en sí la determinación de una comprensión preontológica del ser. De ahí que la ontología fundamental, que está a la base de todas las ontologías, deba ser buscada en la analítica existencial del Dasein". (SyT, 34 p). Cf. Froese, P., On Purpose. How We Create the Meaning of Life, Oxford: Oxford University Press, 2016.

${ }^{14}$ A este respecto, afirma Heidegger: "El ente que tiene el carácter de Dasein en su Ahí de un modo que explícitamente o no, se encuentra a sí mismo en su condición de arrojado. En la disposición afectiva, el Dasein siempre está puesto ante sí mismo, ya siempre se ha encontrado, no en una forma de una auto-percepción, sino en la de un encontrarse siempre afectivamente dispuesto. Como ente que está entregado siempre a su ser, el Dasein queda entregado también al factum de que ya siempre ha debido encontrarse -pero en un encontrarse, que más que un directo buscar, se encuentra en un huir. El estado de ánimo no abre mirando hacia la condición de lo arrojado, sino en la forma de una conversión o una eversión. De ordinario, el estado de ánimo no se vuelve hacia el carácter de carga que el Dasein manifiesta en él, y menos aún cuando se encuentra librado de esa carga en el estado de ánimo elevado. Esta aversión es siempre la que es, en la forma de una disposición afectiva". (SyT, 155 p.). Cf. Froese, P., On purpose. How we Create the Meaning of Life, Oxford: Oxford University Press, 2016. 
DASEIN, PERSONEIDAD, INTERSUbJETIVIDAD Y PERSONA-NÚCleO (III). LA ESTRUCTURA

transcendental discursiva después de Heidegger, en Zubiri, Apel y Polo

\section{El "Dasein" como posibilidad en una estructura transcendental discursiva, según Heidegger}

Heidegger descubre la auténtica naturaleza del Dasein mediante esta segunda estructura transcendental discursiva, que se superpone a la anterior estructura transcendental ontológica, por la que se encuentra arrojado en medio del mundo. En efecto, si en un primer momento, en virtud de la inicial estructura trascendental ontológica, el Dasein se concebía como un "ser en el mundo", abierto en su totalidad a los demás entes, ahora la situación cambia radicalmente en el modo de concebirse, a saber: el Dasein se concibe como un ser arrojado a un mundo con múltiples posibilidades, con la exigencia de elaborar un proyecto de compresión mediante el que sea posible un sometimiento a través del cual se deja afectar por todos los entes por igual, a condición tratar de esquivar el lugar preeminente que anteriormente ocupaba, pasando a retirarse a un lugar muy secundario. En este sentido el Dasein se abre al mundo, a condición de entregarse a las múltiples posibilidades infradotadas que ahora se le ofrecen, sin poderse hacer cargo de ellas, y tratando de esquivar la radical posición de infradotación discursiva como mera posibilidad de existir que ahora se le asigna. ${ }^{15}$

De todos modos, esta aparente pérdida de autonomía, derivada del arrojamiento en el mundo, conlleva además la desventaja de nunca poderse hacer completamente a sí mismo, como hubiera sido de esperar. En su lugar, manifiesta más bien la necesidad de tener que optar por una de esas múltiples posibilidades, radicalmente infradotadas, ante las que inicialmente se encuentra abierto y posteriormente arrojado, sin que haya otra alternativa posible. Sólo así podrá interpretarse a sí mismo como la efectiva realización de una de estas ilimitadas posibilidades de realización incompleta e igualmente fracasadas. En cualquier caso, ello no impide que fenomenológicamente el Dasein tenga que otorgar una prioridad a una de estas múltiples posibilidades sobre el resto, que quedan postergadas a un segundo plano de realización muy accidental. Por eso la apertura de Dasein se focaliza fenomenológicamente alrededor de esta primera posibilidad ahora elegida, la menos mala entre todas, en la medida que muestra una disposición prioritaria a favor de su efectiva consecución. Sin embargo, esta elección conlleva el riesgo de permanecer permanentemente arrojado a esta situación en la que el Dasein inicialmente se encuentra, sin poder evitar que las sucesivas deliberaciones incrementen aún más la presión

\footnotetext{
${ }^{15}$ A este respecto, afirmaba Heidegger: "La disposición afectiva no sólo abre al Dasein en su condición de arrojado y en su estar-consignado al mundo ya abierto siempre con su ser, sino que ella misma es el modo existencial de ser en el que el Dasein se entrega constantemente al "mundo" y se deja afectar de tal modo por él, que en cierta forma se esquiva a sí mismo. La constitución existencial de este esquivamiento será aclarada con el fenómeno de la caída". (SyT, 158 p.). Cf. Сномsку, N., What kind of creatures are we?, New York: Columbia University Press, 2016.
} 
provocada por la angustia existencial y, en definitiva, por el creciente miedo a seguir permanentemente condicionado por esta primera elección. ${ }^{16}$

En cualquier caso, la elección de una de estas múltiples posibilidades infradotadas, no impide que desaparezcan las demás deliberaciones posibles. Precisamente la condición de estar arrojado en un "ser-ahí" hace que todas estas posibilidades sigan subsistiendo, de modo que la elección preferencial de una de ellas, lo único que hace es establecer un orden y jerarquía preferencial entre ellas, haciendo que las demás posibilidades se articulen y se subordinen alrededor de la elegida en primer lugar. Efectivamente, la comprensión (Verstehen) de todas estas posibilidades requiere la subordinación de unas determinadas disposiciones secundarias respecto de otras consideradas principales. Sin embargo, en todos los casos la comprensión de estas múltiples posibilidades infradotadas se genera a partir de la inicial compresión de la situación tan límite en que desde un principio se encuentra el Dasein como "ser-ahí", obligado a tener que elegir la opción menos mala, aunque en realidad ninguna opción consiga sacarle de la situación tan angustiosa en la que se encuentra. Por su parte, el Dasein puede aspirar a otras formas dependientes de conocimiento, como el "explicar", que a su vez están subordinadas a la previa comprensión de la estructura transcendental discursiva en la que el "ahí" del Dasein se inserta. En cualquier caso, la referencia que el Dasein hace a su respectivo "ser-ahí" es la forma más originaria de comprensión, de la cual derivan las demás formas más secundarias de conocimiento, como ahora al menos sucede en el caso del "explicar". Lo prioritario, en cualquier caso, es la comprensión de las múltiples posibilidades igualmente infradotadas que genera el "ser-ahí", dando lugar a un determinado proyecto de "autocomprensión" de su respectivo "ahí", necesariamente incompleto y fragmentario. Posteriormente se jerarquizan y estructuran las diversas posibilidades ónticas que se le ofrecen al conocimiento, ya sea en la forma de comprensión o de explicación, ya sean teóricas o prácticas, ya sean especulativas o discursivas. ${ }^{17}$

\footnotetext{
${ }^{16}$ A este respecto, afirma Heidegger: “La interpretación fenomenológica deberá entregar al Dasein mismo la posibilidad de la apertura originaria y dejarlo, en cierto modo, interpretarse a sí mismo. Ella se limita a acompañar esta apertura, con el fin de elevar existencialmente a concepto el contenido fenomenológico de lo abierto. (...) El fenómeno de la disposición afectiva deberá ser ilustrado más concretamente por medio de este modo determinado que en el miedo". (SyT,159 pp.). Cf. Seubert, H.; Philosophie. Was sie ist und sein kann, Schwabe, Basel, 2015.

17 A este respecto, afirma Heidegger: "La disposición efectiva es una de las estructuras existenciales en que remueve el ser de 'Ahí'. Este ser está constituido co-originariamente con ella, por el comprender (Verstehen). La disposición afectiva tiene siempre su comprensión, aun cuando la termina. El comprender es siempre un comprender efectivamente templado. Lo interpretáramos como un existencial fundamental, con ello se muestra que ese fenómeno es comprendido como un modo fundamental del Dasein. En cambio, el 'comprende' en el sentido de un posible modo de conocimiento entre otro diferente, por ejemplo, del 'explicar', deberá ser interpretado, junto con éste, como un derivativo existencial del comprender pri-
} 
DASEIN, PERSONEIDAD, INTERSUbJETIVIDAD Y PERSONA-NÚCleO (III). LA ESTRUCTURA

transcendental discursiva después de Heidegger, en Zubiri, Apel y Polo

Se establece así una correlación fenomenológica entre el "ahí" del Dasein y su correspondiente "ser en el mundo", de modo que no se podría dar uno sin el otro. Se localiza así el fundamento fenomenológico de la estructura transcendental discursiva del Dasein, ya sea en relación al "ser de los entes", a los otros entes, a los demás Dasein o a su propio Dasein, sin cuya mediación tampoco serían posibles las demás formas de comprensión. En cualquier caso, lo fundamental en todos estos casos es la referencia a un ahí como constituyente intrínseco del Dasein, sin cuya mediación ni se le podría atribuir un "ser en el mundo", ni el conjunto de posibilidades radicalmente infradotadas que se le abren respecto de los otros entes o los demás Dasein, sin excluir tampoco su posible referencia al "ser de los entes" ${ }^{18}$

En cualquier caso, la apertura del Dasein a su correspondiente "ser en el mundo" es recíproca. En este sentido, tan abierto está el Dasein al mundo por apropiarse de un "ahí" por el que se encuentra aherrojado con el mundo, de modo que la referencia al mundo termina formando parte de su propia constitución interna. Pero de igual modo, también es inherente al mundo su apertura al Dasein, dado que el mundo no se podría reconocer como tal mundo sin la apropiación de un "ser-ahí" capaz de relacionarse con el "ser de los entes", con los otros entes y con los demás Dasein, ya se conciban aislados o estableciendo una relación mancomunada entre ellos. De todos modos, esta dependencia del mundo respecto del Dasein no es esencia y, de hecho, ha habido largas épocas geológicas de la historia del Universo donde el hombre no existió. De todos modos, en esas épocas preantropológicas el mundo nunca se habría podido reconocer como tal mundo, si, a pesar de todo, el Dasein no lograra retrotraerse retrospectivamente hasta ellas, otorgándoles una apertura de la que inicialmente carecían. ${ }^{19}$

mario que es con-sustitutivo del ser del Ahí en cuanto tal". SyT, 162 p. Kaeser, E., Artfremde Subjekte. Subjektives Erleben bei Tieren, Pflanzen und Maschinen?, Basel: Schwabe, 2015.

${ }^{18}$ A este respecto, afirma Heidegger: "La investigación hasta ahora desarrollada ya ha tropezado con este comprender originario, pero sin haber sistematizado explícitamente. Que el Dasein existiendo es un Ahí, significa, por una parte, que el mundo es 'ahí'; ser-ahí es su estar-en (el mundo). Y este es, asimismo, 'ahí', (se concibe) como aquello por mor de lo cual el Dasein es. Es el por-mor-del estar abierto al existente por estar-en-el-mundo en cuanto tal, esta aperturiedad ha sido llamada comprender. En la comprensión del por-mor-de esta abierta la coabierta la significabilidad que en él se funda". SyT, 162 p. Cf. Hösle, V.; SuÁrez Müller, F. (Hrsg.), Idealismus Heute. Aktuelle Perspektiven und neue Impulse, Darmstatd: WBG - Wissenschaftliche Buchgesellschaft, 2015.

${ }^{19}$ A este respecto, afirma Heidegger: "La aperturiedad del comprender en cuanto aperturiedad del por-mor-de y de significatividad es cooriginariamente una aperturiedad del ser-en-elmundo. La significatividad es aquello en función de lo cual el mundo está abierto en cuanto tal. Que el por-mor-de y la significatividad estén abiertos en el Dasein significa que el Dasein es el ente que en cuanto ser-en-el-mundo le va su propio ser". SyT, 162 p. Cf. Pritchard, D. Epistemic angst, Princeton/Oxford: Princeton University Press, 2016. 
En cualquier caso, tanto el Dasein como el mundo manifiestan una radical apertura a su propia comprensión, ya sea desde sí mismos o desde una instancia externa que los configura. Al menos así sucede con el mundo o con el propio "ser-ahí" del Dasein, sin poderse ya concebir separados uno de otro. En este contexto la relación de comprender o de entender algo, más que remitirse a un cierto "algo" en cada caso comprendido, expresa fundamentalmente al acto existencial del mismo comprender y, por tanto, la relación del propio Dasein con su respectivo "ahí", sin cuya mediación tampoco se podrían comprender las cosas, ni el mundo, ni a sí mismo. En este sentido, el rasgo fundamental del Dasein reside en su inherente capacidad de comprensión, ya sea volcada hacia el exterior, hacia lo superior o hacia sí mismo. Por su parte, el conjunto de los Dasein, junto a los demás entes, al mundo y al propio "ser de los entes", configuran una estructura transcendental discursiva cuyo rasgo más específico reside en la posibilidad de comprensión existencial que en cada caso se le asigna, como paso previo a poder posteriormente remitirse a "esto" o a "aquello", a concebirse como "algo" o como simplemente "nada". ${ }^{20}$

El Dasein queda así caracterizado como un conjunto infradotado de posibilidades de comprensión, incluida la posibilidad de comprender su propia capacidad o poder de "ser-ahí", cuando perfectamente le podría haber correspondido otro lugar del todo diferente. Se trata de un requisito previo, sin cuya aceptación tampoco sería posible atribuirle ningún otro rasgo, ya sea existencial o esencial. El Dasein en Heidegger no se define como una "cosa" similar a las demás, cuyo rasgo específico más característico pudiera residir en ser "algo" específico que fuera diferente a los demás objetos, según el procedimiento clásico de señalar el género común y la diferencia específica. En su lugar, el Dasein se define más bien desde un punto de vista metafísico, por su apertura ilimitada a un creciente número de posibilidades de comprensión, incluida la propia posibilidad de comprenderse a sí mismo como un "ser-ahí", como un paso previo a poderse concebir como "esto" o "aquello". El Dasein no es tanto un animal racional, al modo aristotélico, sino algo previo y más fundamental, como es la propia posibilidad de comprensión. Sólo así se podrá asignar posteriormente la capacidad de comprenderse a sí mismo como un "algo", que existe junto a los otros entes, a los demás Dasein, al

\footnotetext{
${ }^{20}$ Sobre este asunto, afirma Heidegger: "En el lenguaje óntico se usa a veces en alemán la expresión 'etwas verstehen', 'comprender algo' -en castellano, 'entender de algo' - en el sentido de 'ser capaz de una cosa' de 'poder hacer frente a ellas', de 'saber hacer algo'. Lo existencialmente 'podido' en el comprender no es una cosa, sino el ser en cuanto existo. En el comprender se da existencialmente ese modo de ser del Dasein que es el poder-ser. El Dasein no es algo que está ahí y que tiene, por añadidura, la facultad de poder algo, sino que es primariamente un ser-posible. El Dasein es siempre lo que puede ser y en el modo de su posibilidad". SyT, 162 p. Cf. Agenrn, E.; Die Herausforderung des Negativen. Zwischen Sinnverlangen und Sinnentzug, Basel: Schwabe, 2015.
} 
DASEIN, PERSONEIDAD, INTERSUbJETIVIDAD Y PERSONA-NÚCleO (III). LA ESTRUCTURA transcendental discursiva después de Heidegger, en Zubiri, Apel y Polo

mundo, o al propio "ser de los entes". En este sentido, el Dasein se define a sí mismo como mera posibilidad de comprensión, dado que ninguna de estas capacidades de comprensión se podría llevar a cabo sin disponer previamente de estas ilimitadas posibilidades de apertura que el mismo se apropia. ${ }^{21}$

A este respecto, el Dasein se apropia y hace suya la categoría modal de la posibilidad, concibiéndose a sí mismo como un ente que todavía no es real, ni jamás lo será, por cuanto siempre estará en proceso de llevar a cabo estas ilimitadas posibilidades que lo caracterizan, sin llegar nunca a culminar este mismo proceso. Desde un punto de vista óntico, se encuentra en un permanente intento de afirmarse como si fuera un ente similar a los demás, sin poder en ningún caso conseguirlo. Se le debe concebir, así, como un mero ente posible inferior al resto de los entes efectivamente reales, sin tampoco afirmarse como un mero ente de razón. Por eso está más cerca de la nada que de la posesión de una esencia o de un modo de ser efectivo. Incluso se puede afirmar que tampoco es la nada absoluta, dado que lo poco que tiene es simplemente una simple suma de posibilidades en vías de realización y nunca plenamente culminadas. Por eso el Dasein se concibe como una simple posibilidad existencial en permanente estado de apertura a otras múltiples configuraciones esenciales entre sí diferentes, sin poder realizarlas simultáneamente. De ahí que tenga que permanecer en un estado de mera posibilidad, sin acabar de definirse exclusivamente por una de ellas. Pero a pesar de asignarse una existencia meramente posible y en sí misma infradotada, el Dasein constituye el punto de referencia central sobre el que gira la estructura transcendental discursiva que, a su vez, permite articular al Dasein con los otros entes, con los demás Dasein e incluso con el propio "ser de los ente". En este sentido, para Heidegger, se hace necesario que algo sea entitativamente "nada", concibiéndose como pura apariencia fenoménica, sin poder identificarse deliberadamente con ninguna realidad en concreto, para que pueda permanecer trascendentalmente abierto a todas las demás cosas, sin mostrar una preferencia en exclusiva por ninguna. ${ }^{22}$

${ }^{21}$ A este respecto, afirma Heidegger: “En el comprender se da existencialmente ese modo de ser del Dasein que en el poder ser. El Dasein no es algo que está ahí y que tiene, por añadidura, la facultad de poder algo, sino que es primariamente un ser-posible. El Dasein es siempre lo que puede ser y en el modo de su posibilidad. El esencial poder ser del Dasein concierne a los todos ya caracterizados de ocuparse del "mundo", de la solicitud por los otros y, con ello y desde siempre, al poder ser en relación consigo mismo, por-mor-de sí. La posibilidad que es siempre el Dasein es siempre existencialmente distinguible tanto de la vacía posibilidad lógica, como de la contingencia de algo que está ahí, en cuanto que con éste puede pasar esto o aquello". (SyT, p. 162). Cf. Burgos, j. M.; La experiencia integral. Un método para el personalismo, Palabra, Madrid, 2015.

22 A este respecto, afirma Heidegger: “Como categoría modal del ser-ahí, posibilidad significa lo que todavía no es real y lo que jamás será necesario. Ella es el carácter de lo meramente posible. Es ontológicamente inferior a la realidad y a la necesidad. En cambio, la posibilidad entendida como existencial, es la nada originaria y última determinación ontológica positiva del Dasein; por ahora ella sólo puede ser tratada preparatoriamente como problema, al igual 


\section{La respectividad de la "esencia abierta" en el marco de una estructura transcendental discursiva, según Zubiri}

Zubiri rechaza de forma explícita las propuestas un tanto desconcertantes de Heidegger, aunque inicialmente reconoce sus indudables méritos. A este respecto, hace notar que las propuestas de Heidegger habrían supuesto un avance sustancial respecto de las propuestas de la ontología clásica, ligadas en todo momento al doble punto de vista esencial o existencial desde el que puede ser analizado cada ente en particular. En cambio, Heidegger habría abordado directamente desde un primer momento la pregunta ontológica acerca del ser, sin necesidad de plantear preámbulos previos, que sólo sirven para generar dificultades innecesarias. A este respecto, Zubiri no tiene nada que objetar, sino que más bien tratará de emular un proyecto ontológico de alcance similar, aunque pretenderá darle una orientación diferente. Sin embargo, se trata de una simple cuestión metodológica previa, que no prejuzga, ni para bien ni para mal, nada acerca de la naturaleza del ser o los entes. ${ }^{23}$

El punto de ruptura de Zubiri respecto a Heidegger no se sitúa tanto en el modo de concebir el ser o en los entes, sino en su modo de concebir el $\mathrm{Da}$ sein o ser del hombre. A este respecto, no cuestiona tanto el lugar ontológico privilegiado que Heidegger otorga al hombre respecto de la comprensión del ser, sino el hecho de que le otorgue una capacidad de captar el "ser" mismo. Con el agravante de que para Zubiri la captación del ser se acabaría alcanzando a través del conocimiento del ser-ahí propio del ser humano (Dasein), y más específicamente a través del ser particular que se nos presenta en un ahí. De este modo, Heidegger habría hecho un uso un tanto sesgado de la diferencia óntico-ontológica que en su caso estableció entre los entes y el respectivo "ser de los entes", sin aplicársela al Da-sein o ser del hombre, que según Zubiri no sólo sería el único ente abierto al resto de los entes, sino

que la existencialidad en general. La base fenoménica para poder siquiera verla es el comprender en cuanto poder ser aparente". (SyT, 162-163 pp.). Cf. Gergen, K. J.; El ser relacional. Más allá del yo y de la comunidad, Bilbao: Desclée de Brouwer, 2015.

${ }^{23}$ A este respecto, afirma Zubiri: "Heidegger tiene el incuestionable mérito, no precisamente de haber distinguido el ser y el ente (en forma más o menos turbia, y lo hemos visto, esta distinción transcurre en el fondo de la Escolática y hasta Kant), sino el mérito de haberse hecho cuestión del ser mismo aparte del ente. Pero, ¿cómo se hace cuestión del ser? Esto es lo decisivo. Heidegger sitúa el problema del ser en la línea de la comprensión. Dicho así, sin más, esto es irrecusable. En efecto, sólo mostrándose a sí mismo y desde sí mismo en la comprensión es como puede hablarse del ser; al igual que sólo podemos hablar de los colores viéndolos en sí mismos. Si Heidegger se contentara con decir que hay una comprensión del ser y tratara de explicarla en su irreductible originalidad, no habría la menor objeción de principio que exponer. Pero esto no prejuzga nada del ser mismo". (SE, pp. 441-442). Cf. J.M. Gómez Delgado, La realidad del sentido. Interpretación, normatividad y fenomenología en Heidegger y Zubiri, Granada: Editorial Comares, 2016. 
DASEIN, PERSONEIDAD, INTERSUBJETIVIDAD Y PERSONA-NÚCLEO (III). LA ESTRUCTURA

transcendental discursiva después de Heidegger, en Zubiri, Apel y Polo

que también tendría la virtualidad de acceder al "ser de los entes", en contra de lo que en principio se podría esperar. A este respecto, Zubiri localiza, en las propuestas de Heidegger, una contradicción en sí misma irresoluble, que le acabaría obligando a renunciar a su inicial proyecto metafísica, al menos, con las pretensiones que inicialmente se propuso. En efecto, no se puede establecer una diferencia radical última en sí misma intransitable entre los entes y el correspondiente "ser de los entes", y simultáneamente afirmar que el $D a$ sein tiene un capacidad de describirla, pudiendo conocer ambos extremos de dicha relación: sería lo mismo que reconocer que no se trata de una diferencia radical última, ni de que tiene un carácter en sí mismo intransitable. ${ }^{24}$

Pero, a pesar de estas indudables paradojas y contradicciones, Zubiri comparte con Heidegger un similar rechazo de la substancialización del sujeto pensante, que se produjo a lo largo de la filosofía moderna, especialmente en Descartes. A este respecto, tanto Heidegger como Zubiri conciben al ser humano como una progresiva actualización de posibilidades en permanente estado de constitución efectiva, sin llegar nuca a una configuración plena y definitiva. Pero algo similar les ocurre a las relaciones espacio-temporales, que tampoco llegan a configurar por sí solas una substancia, concretamente un Universo material, como pensó Newton, sino que siempre deben abrirse a un proceso de progresiva actualización de ilimitadas posibilidades, sin poderlas dar por terminadas. O como también le sucedió a la noción de ser en Hegel, que la terminó substancializando, como si se pudiera concebir como un principio subsidente por sí mismo, cuando también debe estar abierto a

${ }^{24}$ A este respecto, afirma Zubiri: "Para Heidegger, el hombre es el ente a cuyo ser pertenece la 'comprensión del ser' de sí mismo y de lo que no es él: pero tanto tratándose de sí mismo como de cualquier otra cosa, no puede confundirse el ser con el ente. $1^{\circ}$ ) Las cosas, comprendidas como tales cosas, son entes, son algo 'óntico'. -Heidegger no habla de cosas sino de entes, pero [...] basta saber que, para Heidegger, cosa es formalmente 'ente' $-.2^{\circ}$ ) Pero el ser es diferente; su dominio es lo 'ontológico'. Es la 'diferencia ontológica' “. SE, p. 439.

A este respecto, afirma Zubiri. “¿Qué es el ser [para Heidegger]? a) El ser no es un ente, sino que es siempre y sólo ser del ente. B) El ente es algo que hay o puede haber sin comprensión, mientras que no hay ser sino en la comprensión del ser Cómo al ser del hombre pertenece la comprensión del ser, resulta que su ser es la presencia misma del ser. Su ser consiste en que el ser (Sein) "está ahí" (Da); es decir, que el ser del hombre es Da-sein. Esta expresión no significa que el hombre sea existencia, en la apelación corriente del vocablo, sino que el hombre es el Da mismo, la presencia del Sein, del ser. El Da es la comprensión misma como presencia del ser. En su virtud, sólo hay ser en cuanto hay Dea-sein, y según el modo como hay Da-sein. No se trata de una presencia como término u objeto de la comprensión, sino que, como la comprensión del ser pertenece al ser mismo del Da-sein, resulta que aquella presencia, es decir, el Da-sein, es, si se quiere, el trascurso mismo del puro ser; El Da-sein es la presencia, en cierto modo 'óntico-ontológica' del ser mismo en su pureza, a diferencia de todo ente. De ahí que para Heidegger, la prerrogativa fundamental del Da-sein en la Ontología". (SE, p. 439-440 pp.). Cf. Amengual, G. (Ed.), Guía Comares de Hegel, Granada: Comares, 2015. 
un proceso de progresiva actualización de ilimitadas posibilidades, sin poderlas nunca dar por definitivamente terminadas. ${ }^{25}$

Las discrepancias de Zubiri respecto de Heidegger surgen especialmente a la hora de formalizar la estructura transcendental discursiva que debe permitir correlacionar y a la vez diferenciar a los diferentes entes entre sí. A su modo de ver, es muy diferente la concepción del ente, cuando lo concebimos en sí mismo, en su estricta realidad, que cuando lo concebimos como un ser que a su vez se correlaciona con los demás entes. En el primer caso se asigna a una cosa o ente una determinada realidad en virtud de sí mismo, sin necesidad de correlacionarse con ningún otro. Por ello la simple suma de realidades no incrementa la que cada ser ya tiene cada ente de suyo, sino simplemente la contextualiza en un determinado ámbito donde tiene lugar. En cambio, en el segundo caso se asigna a una cosa o ente un determinado ser, en la medida que se correlaciona con otros entes manteniendo relaciones de dependencia mutua entre ellos, pero perdiendo gran parte de la independencia y de la realidad que inicialmente se les otorgaba. Por ello la siempre suma de seres puede constituir un modo de transcendencia que está por encima de cada uno de sus elementos que la componen, sin que por ello necesariamente constituyan un ser de naturaleza diferente. ${ }^{26}$

A este respecto, afirma Zubiri: «"Esta distinción entre realidad y ser es la raíz de una importante diferencia en la consideración de lo real. Según estas dos actualidades, la cosa real qua real en su primera y primaria actualidad puede tener una conexión causal con otras cosas reales; la cosa real en su respecto fundante a otras realidades tiene lo que henos llamado páginas atrás "condición": es potencial, actual, necesaria, probable, contingente, libre, etc. Pero esta conexión o respecto causal no es la respectividad transcendental, $\mathrm{y}$, por tanto, esas modalidades y condiciones no conciernen formalmente al ser, sino a la realidad en y por sí misma. En cambio considerada la cosa real como actual en el mundo, esto es, considerarla como actual en su respectividad transcendental, la cosa real tiene ser"» (SE, 435 p.).

\footnotetext{
${ }^{25}$ A este respecto, afirma Zubiri: "Y, en otro orden de problemas, la filosofía moderna, ha sustantivado "la" conciencia. Pero la conciencia no tiene sustantividad ninguna: y ello no porque sólo en acto, sino porque ni tan siquiera es acto, sino tan sólo carácter de algunos actos, de los conscientes. Y no es ningún azar el hecho de que se hayan llevado a cabo casi sistemáticamente estas tres sustantivaciones; la de la conciencia (Descartes), la del espacio-tiempo (Newton, Kant), la del ser (Hegel)". (SE, 437 p.) Cf. Zahavi, D., Self and Other, Oxford: Oxford University Press, 2014.

${ }^{26}$ A este respecto, afirma Zubiri: “De aquí se sigue que una realidad constitutivamente irrespectiva tendría realidad en sentido eminente, pero por eso mismo no tendrá ser. Dios es realidad, esencialmente existente; por tanto, irrespectiva, extramundana. Por eso, de Dios no se puede decir propiamente que "es", no es "on", sino que así como su realidad es extramundana, así también está allende el ser. Es el "sobre-ser", "pro-on" lo llamaban; son toda propiedad los primeros teólogos neoplatónicos". (SE, p. 434).
} 
DASEIN, PERSONEIDAD, INTERSUbJETIVIDAD Y PERSONA-NÚClEO (III). LA ESTRUCTURA transcendental discursiva después de Heidegger, en Zubiri, Apel y Polo

Zubiri discrepa totalmente respecto del modo como Heidegger articula los seres entre sí, atribuyéndoles indiscriminadamente una realidad cada vez más elevada y subsistente, cuando se trata de dos puntos de vista claramente distintos. Al menos, así sucede de un modo paradigmático cuando se compara a los "entes" y el denominado "ser de los entes", cuando la mera superposición sumativa de entes no le añade ninguna dimensión ontológica nueva. Llega incluso a calificar sus propuestas de absurdas, a pesar de reconocer que la "esencia abierta" o personeidad, como ahora se prefiere denominar a la persona, se encuentra en una situación absolutamente límite, carente de los medios necesarios mínimos para poder afrontar una responsabilidad transcendental discursiva, proporcionada al alcance que se le exige. A su modo de ver, el rasgo propio de todo ente, y no sólo de la persona, consistiría en la respectividad recíproca que a su vez mantiene con los demás entes, incluidas las demás personas y el propio "ser de los entes" o Dios. En su opinión, el ser añade la realidad la respectividad fáctica que a su vez mantiene con los demás entes. En cambio, la realidad se reduciría a la consideración absoluta de un ser en cuanto tal. Por eso el ser manifiesta la relación que todo ente, incluida la "esencia abierta" o persona, mantiene a su vez con el mundo del que forma parte. En cambio, la realidad sólo hace referencia a la entidad asignada a cada ser en particular, incluida también la persona. En este sentido el "ser" no es formalmente idéntico a la "realidad", aunque la presupone. El "ser" es la misma "realidad" concebida como un momento del mundo, dado que no podría haber "ser" sin remitirse a un mundo donde un determinado ente se inserta. En este contexto, tanto el ser como el mundo o la "esencia abierta" o persona forman parte de la estructura transcendental discursiva que a su vez configura la realidad en cuanto tal. En efecto, en la medida que la persona determina el ámbito absoluto donde se hace efectiva la operatividad de cada entidad, en esa misma medida se le puede asignar el nivel de realidad que efectivamente le corresponde. O que determina la específica operatividad del mundo como ámbito absoluto donde se insertan los entes en general, constituyendo a su vez el lugar donde se aloja la realidad en su conjunto. O que determina la específica operatividad que la "esencia abierta" o persona se asigna a sí misma, como agente efectivo que a su vez permite que el ser "salga a luz", después de haberle "dado a luz", haciendo a su vez que el ente "venga al mundo". O que determina la específica operatividad asignada a Dios, cuando a su vez hace posible las relaciones de respectividad que se establecen entre los entes, la persona y él mismo, en virtud de la peculiar estructura transcendental discursi$v a$ donde se inserta cada uno de ellos. En cualquier caso, la realidad constituye el momento absoluto que se requiere para que cada ente alcance su propia 
respectividad con los demás entes, sin por ello cuestionar la profunda unidad existente entre todos ellos. ${ }^{27}$

El ser y la realidad se requieren mutuamente, pero se diferencian formalmente. El ser actualiza al ente de un modo respectivo, en las relaciones que necesariamente mantiene con los demás entes, en la medida que a su vez configura un mundo. En cambio, la realidad afirma al ente de un modo absoluto, en cuanto se concibe a cada ente, incluida la persona, o a Dios, con total independencia de los demás. Precisamente el rasgo principal que se atribuye a la persona es esta capacidad de desdoblamiento entre la consideración de los entes en cuanto ser o en cuando realidad. De este modo, la persona se configura como el núcleo central sobre el que gira la estructura transcendental discursiva de los entes. De hecho, la persona permite establecer discursivamente la diferencia que se establece entre el ser y la realidad, entre el plano transcendental y el predicamental, entre la existencia y la correspondiente esencia, según se analice desde el punto de vista de la respectividad o se adopta un enfoque absoluto. En este sentido, para Zubiri como antes para Heidegger, ambas dimensiones del ente son igualmente necesarias Sin embargo, a diferencia de Heidegger, Zubiri otorga una preferencia a la realidad y a la esencia sobre el ser y la relaciones de respectividad que se establecen entre ella. En su opinión, otorgar una primacía al ser supondría una indebida sustantivación en virtud de su mero papel de envolvente de todo lo real, incluidos ahora también la persona y los correspondientes entes de razón, sin tampoco aportar ningún tipo de justificación al respecto. En este sentido, la propuesta de Heidegger se describe como una gigantesca y ficticia absolutización de la noción de ser. Por eso se propone en su lugar concebir al ser como una simple dimensión respectiva de los entes, en contraposición a la respectiva dimensión absoluta de realidad que también presentan. Pasar de una a otra dimensión se convierte en un asunto que exclusivamente compete a la persona en cuanto se afirma como el núcleo central sobre el que gira la estructura transcendental discursiva que regula la operatividad de los entes en general. ${ }^{28}$

${ }^{27}$ A este respecto, afirma Zubiri: “Estar en respectividad con las demás cosas reales qua reales, esto es lo que a mi modo de ver, constituye el ser (incluida la persona). [...] Ser no es sino la condición en la que queda la realidad por el mero hecho de ser, pero el ser mismo es la actualidad de lo real como momento del mundo [...]. Ser, pues, no es formalmente idéntico a realidad, pero presupone la realidad. Realidad es una formalidad absoluta, mientras que ser es un carácter respectivo. Sólo respectivamente tiene sentido hablar de "salir a luz", "dar a luz", "venir al mundo", etc. En cambio, la génesis y nacimiento conciernen a lo real qua real en absoluto". (SE, 434 p.) Cf. Pedrero, M., Dios existe. Las mejores evidencias de una verdad transcendental, Luciérnaga: Barcelona, 2017.

${ }^{28}$ A este respecto, afirma Zubiri: "Ser es la actualidad respectiva de lo real [...]. En su diferencia con la realidad, el ser tiene, pues, un carácter unitario propio. Pero ésta es una unidad meramente respectiva. Es decir, el ser no es una especie de supremo carecer envolvente de todo lo real y de todo ente de razón, con lo cual el orden transcendental sería el orden del ser. Ésta es una gigantesca y ficticia sustantivación del ser. El ser, y correlativamente el no ser, tienen 
DASEIN, PERSONEIDAD, INTERSUbJETIVIDAD Y PERSONA-NÚCleO (III). LA ESTRUCTURA

transcendental discursiva después de Heidegger, en Zubiri, Apel y Polo

Un ejemplo paradigmático de la disociación que ahora se establece entre ser y realidad es el caso de Dios. Para Zubiri, a Dios habría que atribuirle el máximo de realidad, pero no se le puede asignar el ser. De hecho, en su opinión, Dios está absolutamente separado del resto de los entes, sin mantener especiales relaciones de respectividad con ninguno, por lo que no se le puede atribuir el ser. En cambio, habría que atribuirle la máxima realidad entre todas las posibles, ya que subsiste por sí mismo, sin mantener ninguna relación de dependencia o de interacción con ninguno. A este respecto, la realidad de Dios es completamente "extramundana", allende de todo ser. $Y$ en este sentido, ya los primeros teólogos neoplatónicos le denominaron el "sobre-ser", el "pro-on". Por poder, se le podría atribuir la unidad, pero no el ser, ya que sería establecer algún tipo de dependencia del resto de los entes. ${ }^{29}$

En cualquier caso, Zubiri reconoce que Heidegger habría replanteado el problema de la comprensión del ser desde un enfoque fenomenológico y hermenéutico que hasta entonces había sido muy poco habitual. Sin embargo, Zubiri considera que eso no habilita a Heidegger para atribuirse el mérito de haber elaborado una nueva ontología, o al menos de haber mostrado los desenfoques y graves olvidos de la ontología tradicional, cuando en su caso se introducen desenfoques aún mayores. Especialmente cuando pretende alcanzar directamente una comprensión del ser sin contar para nada con la esencia, ni con la realidad efectiva de las cosas en su singularidad concreta, enredándose en un sinnúmero de problemas que perfectamente se podrían haber evitado. O cuando pretende justificar una estructura transcendental discursiva que le permitiera determinar cuándo la persona se atribuye a sí misma una capacidad adecuada o no de regular las relaciones que a su vez mantiene con ella misma, con los demás entes, con sus propios semejantes o con el propio "ser de los entes". En este contexto, Heidegger no habría elaborado tanto una ontología, sino a lo máximo una teoría del conocimiento ontolológico que, además, acabaría resultado muy problemática. ${ }^{30}$

carácter meramente respectivo; las "cosas" reales son, pero "el" ser no tiene sustantividad". (SE 436 p.) Cf. Nicolás, J. A.; Grondin, J. (Eds.), Verdad, Hermenéutica, Adecuación, Tecnos: Madrid, 2016.

${ }^{29}$ A este respecto, afirma Zubiri: “De aquí se sigue que una realidad constitutivamente irrespectiva tendría realidad en sentido eminente, pero por eso mismo no tendrá ser. Dios es realidad, esencialmente existente; por tanto, irrespectiva, extramundana. Por eso, De Dios no se puede decir propiamente que "es", no es "on", sino que así como su realidad es extramundana, así también está allende el ser. Es el "sobre-ser", "pro-on" lo llamaban con toda propiedad los primeros teólogos neoplatónicos". (SE, p. 434). Cf. JAGO, M. (Ed.), Reality Making, Oxford: Oxford University Press, 2016.

30 A este respecto, afirma Heidegger: “Heidegger sitúa el problema del ser en la línea de la comprensión. Dicho así, sin más, es irrecusable. En efecto, sólo mostrándose a sí mismo y desde sí mismo, en la comprensión es como puede hablarse del ser, al igual que sólo podemos hablar de los colores viéndolos en sí mismos. Si Heidegger se contentara con decir que hay una comprensión del ser y tratara de explicarla en su irreductible originalidad, no habría la menor 
Además, Zubiri presupone a lo largo de todas estas reflexiones la validez de un conjunto de nociones heideggerianas muy precisas, a saber: la singularidad de la persona por ser el único entre todos los entes capaz de comprenderse a sí mismo y a los demás entes, en la medida que configuran un mundo y que a su vez se remiten a un "ser de los entes" que los fundamenta. Pero a su vez Zubiri también presupone en este contexto la validez de la diferencia radical última que Heidegger establece entre los entes y el respectivo "ser de los entes" en el que todos están insertos, incluida la persona humana. Sin embargo, Zubiri discrepa respecto de Heidegger a la hora de interpretar estas nociones: $\left.1^{\circ}\right)$ Los entes, antes que concebirse como seres, se deben concebir como cosas, dado que sin la realidad de su correspondiente esencia tampoco se les podría asignar una respectividad en relación a los demás entes, incluido el "ser de los entes" o la propia persona; $2^{\circ}$ ) La diferencia óntico-ontológica que Heidegger establece entre los entes y el correspondiente "ser de los entes" no se establece en el ámbito conceptual de la realidad de las respectivas esencias, sino en el ámbito estrictamente ontológico, como es el peculiar acontecer ascensional meramente respectivo del ser. Se trata efectivamente de dos distintos, pero que no genera una diferencia radical última intransitable, como pretende Heidegger, sino que más bien una requiere a la otra. Es más, en el caso de aceptar las propuestas de Heidegger, tampoco se podría hablar de una estructura transcendental discursiva que pudiera estar abierta a concebir el Dasein de múltiples formas, según se la conciba como una simple posibilidad óntica, o incluso como una nada, como con tanto énfasis propone. En su lugar se debería concebir al Dasein como una pretensión inútil de pretender superar una diferencia de suyo intransitable respecto al "ser de los entes", al modo como acabará ocurriendo en Sartre. ${ }^{31}$

Zubiri tampoco atribuye un carácter subjetivo o inmanentista al ser en Heidegger. En su opinión, Heidegger habría concebido al ser un carácter extramental y estrictamente metafísico, que a su vez se afirma como fundamento de toda la realidad. Se concibe al ser como la luz que también se afirma como el requisito de la visibilidad de todos los objetos. Y en este sentido, el

objeción de principio que oponer. Pero eso no prejuzga nada acerca del ser mismo. Lo que con ello se habría logrado no es una Ontología, sino una Teoría del Conocimiento ontológico, por así decirlo. Sin embargo, Heidegger busca una Ontología". (SE, 441-442 pp.). Cf. TurTON, G., Evidential Uncertainty in Causation in Negligence, Hart, Oxford: Bloomsbury, 2016.

${ }^{31}$ A este respecto, afirma Heidegger: "Para Heidegger, el hombre es el ente a cuyo ser pertenece la 'comprensión del ser' de sí mismo y de lo que no es él. Pero, tanto tratándose de sí mismo como de cualquier otra cosa, no puede confundirse el ser con el ente. $1^{\circ}$ ) Las cosas, comprendidas como tales cosas, son entes, son algo 'óntico'. [...] 2 2 ) Pero el ser es diferente; su dominio es lo ontológico. Es la diferencia (óntico)-ontológica". No es una diferencia conceptual, sino un acontecer diferenciante, un acontecer ascensional, que lleva de la comprensión del ente a la comprensión del ser y nos mantiene en ésta". (SE, 438-439 pp.). Cf. PLA VArGas, L. (Ed.), La actualidad de Marx, Barcelona: Cuadernos para el análisis 44, Horsori, 2016, 
DASEIN, PERSONEIDAD, INTERSUbJETIVIDAD Y PERSONA-NÚCleO (III). LA ESTRUCTURA transcendental discursiva después de Heidegger, en Zubiri, Apel y Polo

ser se concibe como el fundamento que permite captar la presencia de todos los entes, aunque su origen y procedencia siga siendo un enigma que en su caso aún no ha podido resolver. En este contexto está claro que la luz intelectual conoce a unos entes extramentales que subsisten por sí mismos, aunque la conexión que se establece entre ellos siga siendo un enigma aún no resuelto. Sin embargo, Zubiri también hace notar cómo el último Heidegger tampoco acabó de resolver el llamado problema del "acaecer del sentido", por tener en cuenta los requisitos de validez que también se deben exigir a estos anteriores procesos de iluminación para que realmente alcancen el objetivo que se proponen, sin terminar viendo frustradas las grandes expectativa que despiertan. ${ }^{32}$

\section{La comprensión reflexiva a priori de la estructura transcendental discursiva en Apel}

Apel también reacciona ante las propuestas un tanto desconcertantes de Heidegger, aunque lo haga con menos virulencia que Zubiri. En su opinión, hay que reconocer las aportaciones de Heidegger al análisis de la estructura transcendental discursiva a la hora de fijar las exigencias que debe cumplir la correspondiente crítica de sentido, cuando determina cuándo una proposición cumple o no las condiciones para poder asignarle un determinado significado, sea o no metafísico. En este sentido, las propuestas de Heidegger y después Gadamer habrían obligado a un replanteamiento del análisis crítico-transcendental de las posibilidades del propio conocimiento, ampliándolo desde su mismo punto de partida para dar cabida a otras exigencias de carácter simplemente fenomenológico, hermenéutico o estrictamente metafísico que entonces no se tuvieron en cuenta. Concretamente, se debe admitir desde un inicio la posibilidad que siempre cabe de ampliar el horizonte hermenéutico de expectativas y pretensiones, sin circunscribirse exclusivamente al ámbito de la ciencia físico-matemática newtoniana, sino admitiendo también otros posibles desarrollos de la ciencia experimental, de la fenomenología, de la hermenéutica o de la propia metafísica, al modo ahora indicado por Hei-

\footnotetext{
${ }^{32}$ A este respecto, afirma Zubiri: "Esto no significa que el ser (para Heidegger) sea subjetivo. Todo lo contario. Esta presencia del ser en la comprensión, en el Da-sein, es la verdad del ser. El Da es la patencia misma. Esta verdad es, pues, el ser del Da-sein. [...] Volviendo a la expresión con que Aristóteles expone la acción del "nous noeticos", a saber que es iluminación [...], Heidegger nos dirá que la presencia del ser en el Da-sein, es como la luz. Es la verdad que es el ser del Da-sein no está presente como una cosa, sino que el "ser es la luminidad misma". El ser es la luminidad de todo ente y lo que no sólo no es subjetivo, sino que "el ser es los transcendente mismos". Y por esto, le comprensión del ser es la comprensión transcendental". (SE, 440-441).
} 
degger y Gadamer. Todo ello obligará a introducir una transformación en el modo de concebir el alcance y el sentido de la propia filosofía transcendental, y en sus conceptos más afines, como ahora ocurrirá con la propia noción de a priori o sujeto o más bien co-sujeto transcendental, por sólo señalar los representativos. ${ }^{33}$

En este contexto, la expresión "pre-ser-se" sólo indica la capacidad del "Dasein" de apropiarse aquellos procesos fenomenológicos y hermenéuticos que hacen posible la "constitución" de sentido y la peculiar "pre-estructura del comprender", o el particular "por mor-de" de la "cura", o del "ser deudor", que ahora se asigna a sí mismo. En efecto, en todos estos casos el propio "Dasein" debe reconocer desde un principio la posición tan singular que ocupa en el "mundo" o incluso respecto del propio "ser", en la medida que se concibe como el auténtico protagonista de las peculiares relaciones que mantiene con cada uno de los "entes" o incluso con los propios "hechos", ya contribuya poco o mucho, sin tampoco poder ya eludir la responsabilidad que todo ello genera. Quiera o no quiera, a él le corresponde hacerse responsable de la situación privilegiada de la que dispone en relación al resto de los "entes" o incluso de los "hechos" o "eventos" que acaecen en el "mundo". Es decir, se debe hacer responsable de dotarse a sí mismo y al mundo que le rodea de una "constitución de sentido" y de una "pre-estructura" del comprender", que a su vez debe estar conforme con la peculiar libertad transcendental ontológica que se asigna a sí mismo. ${ }^{34}$

\footnotetext{
${ }^{33}$ A este respecto, afirma Apel: "Heidegger ha prestado una contribución imborrable al problema 'hermenéutico-transcendental' de la constitución del sentido; pero, por otra parte -y según su propia confesión- se ha equivocado con respecto al problema de la verdad -por tanto, con especto de la validez-. La filosofía ha de volver nuevamente a Kant, pero transformando la filosofía transcendental de modo que cuente también, entre otras cosas, con la ampliación hermenéutico-transcendental del horizonte, realizada por Heidegger y Gadamer". (TF, I, 33 p.). Cf. Gadamer, H.G., Poema y diálogo, Barcelona: Gedisa, 2016, 159 pp.

${ }^{34}$ A este respecto, afirma Apel: "Ya en la expresión "pre-ser-se" queda patente, a mi juicio, que Heidegger en Ser y tiempo todavía no había roto totalmente la relación con una filosofía transcendental de la "subjetividad" en sentido kantiano. Por ello, en Kant y el problema de la metafísica pudo conciliar todavía el "carácter de proyección" del comprender que se transciende a sí mismo y a todo ente, con la "espontaneidad" de una "imaginación transcendental" en sentido kantiano. También la "interpretación" del "pre-ser-se" como "cura", tal y como exige el "por-mor-de-qué" del "ser-en-el-mundo", y sobre todo el discurso sobre el ya siempre "ser deudor" del ser-ahí, prueban que en aquel momento pudo no ser desacertado entender la "preestructura" del comprender, al menos también, como un problema de la identidad del hombre consigo mismo, que se puede aceptar o rechazar. En ello podía haberse descubierto enteramente el problema de reconstruir, a la vez empírica y normativamente, las condiciones de posibilidad y validez de a comprensión del mundo y de sí mismo, involucradas en la "preestructura"; problema que tiene que ser resuelto también con medios científicos". (TF, I, 37 p.). Cf. Breitenstein, von Urs HRg.); Verantwortug - Freiheit und Grenzen. Interdisziplinare Veranstaltunungen der Aeneas-Silvius-Stiftung, Vortrage der Aeneas-Silvius-Stiftung an der Universität Basel - I, Schwabe, Basel, 2016.
} 
DASEIN, PERSONEIDAD, INTERSUbJETIVIDAD Y PERSONA-NÚCleO (III). LA ESTRUCTURA transcendental discursiva después de Heidegger, en Zubiri, Apel y Polo

Evidentemente, Apel considera que, en Ser y tiempo, Heidegger dio un paso de gigante respecto al modo como la filosofía crítico-transcendental puede llevar a cabo una efectiva justificación de las condiciones de posibilidad y de sentido del correspondiente proceso de comprensión hermenéutica. La novedad principal estriba en que ahora el sujeto ya no se afirma como un sujeto transcendental extraño que pudiera situarse fuera del mundo, cuando de hecho es uno de los protagonistas principales que entran a formar parte de la configuración de este tipo de procesos. Sin embargo, su papel no estriba en generar un proceso de producciones subjetivas de la conciencia pura, como Husserl habría denunciado en las propuestas de tipo kantiano. En su lugar se considera que Heidegger habría puesto de manifiesto cómo la "pre-estructura 'a priori' de comprensión" que hace posible estos procesos de comprensión hermenéutica tiene por naturaleza un carácter subjetivo. Sin embargo, no ocurre así con los procesos fenomenológicos de "constitución de sentido" a los que ahora se asigna un carácter en sí mismo objetivo, pues se constituyen o se han constituido ya siempre para nosotros, sin poder alterar este carácter ya-dado o configurado que ahora se les asigna. Hasta el punto que lo único que cabe hacer en esta situación tan constreñida es decidir si se pone en ejercicio la propia obra de "despejamiento" de todos aquellos condicionantes que a su vez impone el llamado "a priori" lingüístico, incluido el "despojamiento" del "ahí" que a su vez constituye el peculiar modo de ser del "Dasein". En cualquier caso, Apel atribuye a Heidegger una reflexión de tipo crítico-transcendental que le habría permitido postular un "a priori" perfecto" capaz de justificar un proceso de convergencia progresiva entre los distintos factores que confluyen en el proceso de comprensión recíproca. Hasta el punto de tampoco poder introducir ningún tipo de fisura entre estos distintos factores, ya sean de tipo fenomenológico, hermenéutico, crítico-transcendental o simplemente metafísico, teniendo que postular una progresiva mejor articulación entre ellos. Sin embargo, ahora también es posible que no se pudieran introducir, como de hecho terminará ocurriendo en la última época de Heidegger, cuando atribuyó la aparición inevitable de este tipo de fisuras, al carácter inexorable del "destino del ser", sin que ya sea posible ejercer un control efectivo sobre este tipo de procesos. ${ }^{35}$

\footnotetext{
${ }^{35}$ A este respecto, afirma Apel: "La sugestiva forma heurística de pensar, característica de Ser y tiempo, que se traduce en la reflexión sobre el perfecto 'a priori' del 'pre-ser-se-ya' del 'ser-ahi' como 'ser-en-el-mundo' que se comprende en una situación, inició un nuevo estilo de reflexión transcendental e impidió explicitar el problema de la 'constitución' transcendental, planteado por Husserl, como un problema de 'producciones' subjetivas de una 'conciencia pura'. En realidad es incorrecto desde un punto de vista fenomenológico, hablar de 'construcción' como un acto subjetivo: los fenómenos se constituyen o bien se han constituido ya siempre para nosotros. En nuestros actos subjetivos tenemos que responder ya siempre al mundo constituido -al 'despojamiento' (Lichtung) del 'ahí'-. Esta situación básica del 'pre-ser-se' es de hecho 'irrebasable' y en ella pueden registrarse los factores cuasi-transcendentales de la 'pre-estructura' del com-
} 
De todos modos, Apel hace notar cómo el propio Heidegger acabó malinterpretando el alcance y el sentido otorgado a algunas de sus propuestas más significativas. Por ejemplo, el sentido otorgado a la comprensión hermenéutica, como si tratase de un modo de comportarse del sujeto o de una simple propuesta metodológica similar a las que se pueden formular de las ciencias experimentales, cuando en realidad se trata de algo más decisivo: el propio acto de "comprender", ya se dirija a los entes en general o al "ser de los entes" en especial, manifiesta más bien un modo de ser del protagonista de ese mismo proceso, con independencia de que se conciba como un sujeto, como un co-sujeto o como una comunidad de comunicación compartida por todos los afectados por un determinado discurso, como ahora se va a proponer. En cualquier caso, el propio acto de comprender ya presupone la mediación de un "pre-estructura" del comprender que a su vez hace posible la comunicación humana semiótica, dado que, sin la existencia de un lenguaje, de una comunidad de interlocutores y de los consiguientes co-sujetos de un determinado discurso, tampoco podría hablarse del respectivo proceso de comprensión. En este sentido, Heidegger habría prolongado el análisis de los presupuestos que están sobreentendidos en la lógica de la ciencia, sin quedarse solamente con señalar sus presupuestos de carácter formal, sino reconociendo también otros principios de marcado carácter existencial. En este contexto, nada que objetar, y las propuestas de Heidegger habrían significado un avance muy importante respecto de las propuestas habituales a este respecto de la denominada lógica y metodología de la ciencia. ${ }^{36}$

Pero a pesar de este avance importante, Heidegger se habría quedado corto en su pregunta acerca de la "pre-estructura" transcendental del comprender. Como él mismo acabaría reconociendo, sus análisis le permitirían justificar de un modo a priori determinados elementos transcendentales de los que se compone dicha "pre-estructura", como por ejemplo ahora sucede con la denominada "fusión de horizontes" o la mediación que el pasado ejerce en el pre-

prender; como, por ejemplo, el 'a priori' lingüístico. ¿No es, por tanto, también reconstruible como algo de lo que tenemos que responsabilizarnos? ¿No significa también este 'ya siempre' del perfecto apriorico que hay condiciones de posibilidad del comprender que todavía deben justificarse como condiciones de validez del comprender, de tal modo que, siendo momentos fundamentales de la 'finitud' o del 'estado de yecto' del ser-ahí, no sólo pueden atribuirse sólo a un 'acontecer del ser' o al 'destino del ser'?". (TF, I, 36-37 p.) .Cf. Antweiler, C., Our Common Denominator. Human Universals Revisited, New York: Berghahn, 2016.

${ }^{36}$ A este respecto, afirma Apel: "En este punto es preciso abordar, sin duda, la invocación de Gadamer a Heidegger, es decir, la tesis de que el 'comprender' como tal 'no es un modo de comportarse del sujeto, sino el modo de ser del ser-ahí mismo'. Es evidente que esta idea dominante en la filosofía heideggeriana se identifica esencialmente con la 'pre-estructura' del comprender, que ya hemos expuesto, y a la que atribuimos hacer reaccionado eficazmente contra la reducción de la gnoseología de procedencia kantiana a la 'lógica de la ciencia' o a la 'metodología' “. (TF, I, 35, 36 pp.). Cf. Drakeman, D., Why We Need the Humanities, Basingstoke (UK): Palgrave MacMillan, 2016. 
DASEIN, PERSONEIDAD, INTERSUbJETIVIDAD Y PERSONA-NÚCleO (III). LA ESTRUCTURA transcendental discursiva después de Heidegger, en Zubiri, Apel y Polo

sente. Sin embargo, Heidegger no habría abordado, al menos según Gadamer, el análisis de los consiguientes requisitos a priori de validez que se deben exigir a dicha comprensión para que pueda ser efectiva desde un punto de vista comunicativo respecto de otros posibles interlocutores de dicho discurso. Especialmente cuando se advierte la necesidad de tomar un conjunto de decisiones que deben cumplir determinados requisitos de validez, si se pretende que dicho proceso de comprensión conduzca a un buen puerto. En este sentido, Gadamer mostraría la necesidad de prolongar la "hermenéutica transcendental" de Heidegger, a fin de justificar otros criterios complementarios de validez que a su vez se deben respetar, a fin de lograr una efectiva mejor comprensión, y no simplemente una comprensión diferente, como al final podría acabar sucediendo con las propuestas de Heidegger. En definitiva, no es suficiente con pretender garantizar la mera posibilidad de una comprensión, sino que además se hace necesario justificar su efectiva validez, sin conformarse simplemente con lograr un proceso de comprensión diferente. ${ }^{37}$

Apel, siguiendo a Gadamer, comprueba así la necesidad de localizar una "pre-estructura" transcendental discursiva que no sólo garantice la posibilidad de una comprensión recíproca entre los distintos interlocutores afectados, sino que también pudiera garantizar de un modo a priori de validez, sin cuyo cumplimiento el proceso de comprensión se podría volver un despropósito son sentido alguno. Especialmente cuando se comprueba la importancia que tiene la fijación de determinadas reglas que sean de obligado cumplimiento para todos los que pretenden formar una comunidad, ya se haga por intereses de carácter científico-técnico, humanístico-cultural o simplemente comunitario-compartido, al modo señalado por Wittgenstein. A este respecto, y parafraseando a Sartre, estamos condenados al acuerdo intersubjetivo. De todos modos, se trata de un proceso acumulativo que se nutre de sucesivas aportaciones individuales cuya demostración de validez debe ser responsabi-

\footnotetext{
${ }^{37}$ A este respecto, afirma Apel: "Intentemos aplicar las consecuencias, obtenidas a partir de una revisión crítica de Heidegger, a la pregunta formulada por Gadamer: '¿cómo es posible la comprensión?'. En la medida en que debemos plantear esta pregunta, junto con Gadamer, 'al conjunto de la experiencia humana en el mundo y de la praxis vital', me parece que constituye la pregunta fundamental de una 'hermenéutica transcendental', es decir, de una filosofía transcendental que reflexiona sobre la 'pre-estructura' de la comprensión en todas las formas de conocimiento científicas y pre-científicas. Pero ello implica también que no podamos explicitar la pregunta por la posibilidad de la comprensión sin plantear, a la vez, la pregunta metodológicamente relevante por la validez de la comprensión. Lo cual, aplicado a Gadamer, significa lo siguiente: Es insuficiente a priori querer contestar a la pregunta por la posibilidad de la comprensión mostrando la estructura del acontecer del ser (de la fusión de horizontes o de la mediación entre el presente y el pasado), que debe realizarse en la estructura del acontecer, sea en la comprensión adecuada sea en la inadecuada. [...] Por tanto, [...] es necesario especificar un criterio para el posible progreso en la comprensión". (TF, I, 41, 42 p.). Cf. García-Carpintero, M.; Torre, S., About Oneself. 'De Se' Thouht and Communication, Oxford: Oxford University Press, 2016.
} 
lidad de cada uno. Sin embargo, el proceso final debe conducir a un acuerdo intersubjetivo cada vez más amplio y solidario, sin que ya tenga sentido el pretender refugiarse en un solipsismo inmanentista, ya se formule al modo cartesiano, fenomenológico o simplemente positivista lógico. ${ }^{38}$

En este sentido, según Apel, el proceso de interpretación hermenéutica y fenomenológica siempre se encuentra constituido de un modo a priori por un cuerpo y por una peculiar forma de reflexión semiótica o lingüística, que inevitablemente se hace presente en cualquier acto de habla referido a una experiencia sensible. Se trata de factores que limitan de un modo relacional cualquier posible comunicación recíproca respecto de un hipotético interlocutor, dado que su mediación es absolutamente indispensable. En cualquier caso, resulta imposible pretender evitar los múltiples condicionamientos semióticos y prejuicios unilaterales que inevitablemente se hacen presentes en estos casos. Sin embargo, se trata del único modo posible para tratar de evitar el solipsismo comunicativo que se hizo presente en el inmanentismo cartesiano, por acabar provocando dificultades irresolubles que a su vez vinieron generadas por recurrir a una estructura transcendental discursiva totalmente inapropiadas. De hecho, dicha estructura cartesiana se pretendía justificar en nombre de una simple relación sujeto-objeto, dejando totalmente de lado la relación sujeto-objeto-cosujeto que en todos estos casos se debe presuponer. En cualquier caso, no se puede llevar a cabo un proceso de comprensión de un ente en particular o del "ser de los entes" en especial, como propuso Heidegger, sin tener en cuenta a determinados factores somáticos y semióticos que a su vez mediatizan este tipo de procesos. ${ }^{39}$

${ }^{38}$ A este respecto, afirma Apel: "Se trata de la 'preestructura' hermenéutica de una filosofía transcendental que no parte -como el idealismo transcendental kantiano- de la hipóstasis de un 'sujeto' o 'conciencia en general' como garante metafísico de la validez intersubjetiva del conocimiento, sino que parte del siguiente supuesto: dado que 'uno sólo y de una sola vez no puede seguir una regla' (Wittgenstein), estamos condenados a priori al acuerdo intersubjetivo, aunque cada uno de nosotros deba comprenderse en el mundo por su cuenta y llegar a conocimientos válidos sobre las cosas y sobre la sociedad en virtud de esta 'precomprensión'. En esta concepción que implica una teoría consensual del acuerdo lingüístico acerca del sentido y de la posible verdad, radica, a mi juicio, la superación del 'solipsismo metódico' que ha desorientado la teoría filosófica del conocimiento, al menos, desde Ockham y Descartes hasta Husserl y B. Russell". (TF, I, 55, 56 p.). Cf. Broch-Due, V.; Ystanes, M. (Eds.), Trusting and its Tribulations. Interdisciplinarity Engagements with Intimacy, Sociality and Trust, New York: Berghahn, 2016.

${ }^{39}$ A este respecto, afirma Apel: “Las condiciones de posibilidad y validez del conocimiento, que acabamos de mencionar, no pueden, por una parte, reducirse únicamente a funciones lógicas de la conciencia, pero, por otra parte, tampoco pueden atribuirse al objeto del conocimiento que ha de ser conocido, puesto que ya siempre se presuponen en todos conocimiento de objetos. La relación cartesiana sujeto-objeto no basta para fundamentar una antropología del conocimiento: una pura conciencia del objeto, tomada por sí sola, no puede extraer del mundo ningún sentido. Para lograr una constitución del sentido, la conciencia -esencialmente 'excéntrica'- debe comprometerse céntricamente, corporalmente, aquí y ahora: cada constitución de sentido remite a un punto de vista, y esto significa nuevamente, a un compromiso 
DASEIN, PERSONEIDAD, INTERSUbJETIVIDAD Y PERSONA-NÚCleO (III). LA ESTRUCTURA

transcendental discursiva después de Heidegger, en Zubiri, Apel y Polo

De hecho, Apel reconoce la existencia de mediaciones a priori que condicionan la estructura transcendental discursiva del propio conocimiento humano. A este respecto, el conocimiento del ente siempre está a su vez mediada por dos condicionamientos inevitables que se hacen presentes en cualquier proceso de conocimiento: el ahora llamado a priori corporal del conocimiento que en nuestra actual realización del conocimiento requiere asumir unos determinados "compromisos" previos acerca del alcance y los presupuestos de dicho conocimiento, según se le pretenda otorgar o no un determinado alcance óntico, ontológico o incluso metafísico, sin poder ya eludir una toma de decisiones de este tipo. Y, por otro lado, el llamado a priori reflexivo o de la conciencia, mediante la que se comprueba la estructura transcendental discursiva que a su vez regula las relaciones que un determinado sujeto mantiene con su correspondiente objeto, así como con los respectivos cosujetos, sin poder eludir tampoco este tipo de mediaciones. De hecho, se trata de dos a prioris antagónicos, que se oponen polarmente, de modo que no se pueden advertir simultáneamente los condicionantes que nos impone el recurso a la experiencia, y los que derivan del uso en común de un mismo lenguaje, como tampoco se puede considerar el peculiar significado otorgado a una observación empírica, y reflexionar sobre los presupuestos semióticos que la han hecho posible. Una cosa es analizar la experiencia y otra determinar la estructura subyacente a un determinado uso del lenguaje, dado que en ambos casos se deben asumir un tipo de compromisos y ejercer un tipo de reflexiones teóricas totalmente distintas. En este sentido, la reflexión teórica y la ulterior aplicación práctica se necesitan mutuamente, pero en nuestras actuales condiciones históricas conllevan pautas de realización opuestas, que sólo paulatinamente se pueden armonizar. ${ }^{40}$

Apel considera que este tipo de prolongaciones de las propuestas heideggerianas conseguirían superar los planteamientos tradicionales, ya sea de la mística del "logos" presente en la filosofía neoplatónica cristiana y que se habían visto prolongados en la filosofía transcendental kantiana o en la

corporal de la conciencia cognoscente". (TF, II, p.). Cf. Bermudo, J. M. (Ed.), El marxismo en la postmodernidad, Barcelona: Cuadernos para el análisis 42, Horsori, 2016.

40 A este respecto, afirma Apel: "A mi juicio, el a priori corporal del conocimiento se encuentra en una relación de complementariedad con el a priori de la conciencia: es decir, en el conjunto del conocimiento de ambas condiciones de posibilidad del mismo se complementan mutuamente de un modo necesario, pero en la actual realización del conocimiento o bien domina el a priori corporal o bien el a priori de la conciencia: 'conocimiento mediante reflexión' y 'conocimiento mediante compromiso' se oponen entre sí polarmente. Por ejemplo, yo no puedo a la vez extraer del mundo un aspecto significativo y reflexionar sobre el punto de vista que debo adoptar para ello. Toda experiencia -también y precisamente la experiencia experimental de la ciencia natural, experiencia que está dirigida teóricamente- es primariamente conocimiento mediante compromiso corporal; toda construcción teórica es primariamente conocimiento mediante reflexión". (TF, II, 94 p.). Cf. Alba Rico, S., Ser o no ser (un cuerpo), Barcelona: Seix Barral, 2016. 
filosofía de lo absoluto hegeliana. Para ello sería necesario llevar a cabo una transformación en su crítica de presupuestos, de modo que la referencia a un "yo" transcendental o a un "yo" absoluto, se sustituyera por la referencia al ideal regulativo irrenunciable de una ilimitada comunidad ideal de comunicación donde se logre un acuerdo efectivo acerca de los resultados alcanzados en la experiencia, y de la propia comunicación lingüística, a diferencia de lo que acaba ocurriendo en las propuestas finales de Heidegger, donde la aceptación de este tipo de ideales regulativos se hace cada vez más imposible. ${ }^{41}$

Este tipo de propuestas abren a Apel nuevos horizontes de reflexión, que le alejan progresivamente de los planteamientos de Heidegger. Sin embargo, Apel considera que, de haberlos aceptado, habría otorgado un sentido final muy distinto a su propuesta inicial de fomentar una apertura ilimitada a un horizonte de comprensión del ser cada vez más ilimitada. Sin embargo, Apel considera que Heidegger acabó haciendo un planteamiento sesgado de tales procesos de apertura respecto del posible sentido compartido que podría acabar teniendo una efectiva comprensión del ser, sin acabar de orientarlos hacia un "despojamiento" de su efectivo sentido en cada caso concreto y hacia una efectiva mejor comprensión de los distintos significados que se otorgan a los entes. En vez de postular una efectiva complementariedad entre los respectivos procesos de "desocultación" y "ocultación" que se hacen presentes en los procesos de investigación heurística, acabó optando por establecer una cada vez más irreconciliable contraposición entre ellos, de modo que cuanto más creemos avanzar en el proceso de respectivo conocimiento más nos alejamos del auténtico sentido, que se debería otorgar a cada uno de estos significado ${ }^{42}$.

${ }^{41}$ A este respecto, afirma Apel: "En esto radica, a mi juicio, la verdad 'superada' de la tradición cristiano-neoplatónica de la mística del 'logos' todavía presente en la doctrina kantiana del 'yo transcendental' (e inteligible) pero, sobre todo, en la consumación hegeliana de una reflexión transcendental, que se realiza en la pretensión del saber que se sabe a sí mismo). Sin embargo, al autocerciorarse transcendental de la verdad, característico de los 'grandes pensadores' de la filosofía apriorística del 'sujeto', sólo puede ser válido a priori -según nuestros supuestos- en los siguientes términos: si conduce a la idea de que cada uno de nosotros, para todos los conocimientos con contenido efectivo, dependen de la experiencia empírica y del ilimitado acuerdo con otros acerca del sentido y verdad de la experiencia. [...] Por tanto, en el a priori de la comunidad del acuerdo, el género humano como sujeto cuasi-transcendental de la verdad frente a los aconteceres del sentido en la historia del ser -por más inmanipulables que pudieran ser en cuanto aconteceres de sentido- recupera su propio puesto de responsabilidad solidaria, que parece perder en la filosofía de Heidegger". (TF, I, 57,58 p.). Cf. Hanna, R., Cognition, Content, and the 'A Priori'. A Suty in the Philosophy of Mind and Knowledge, Oxford: Oxford University Press, 2016.

${ }^{42}$ A este respecto, afirma Apel: "A la luz de esta construcción queda patente que Heidegger valoró equivocadamente su gran descubrimiento: que la 'apretura' (Eröfnung) del 'sentido' ha de preceder realmente a la 'conformidad' de los enunciados, tal y como exige la apertura (Erschlossenheit) hermenéutica del ser-ahí o los horizontes individuales de la 'significatividad'. [...] Únicamente en el caso de la verdad de los enunciados hay una 'diferencia' entre la instancia 
DASEIN, PERSONEIDAD, INTERSUbJETIVIDAD Y PERSONA-NÚCleO (III). LA ESTRUCTURA transcendental discursiva después de Heidegger, en Zubiri, Apel y Polo

En este sentido, Apel acabará siendo muy negativo respecto del uso que el último Heidegger acabó otorgando a la estructura transcendental discursiva sobre la que se fundamenta el conocimiento de los entes en general y del ser de los entes en especial. En su opinión, la última filosofía de Heidegger reflexionó casi exclusivamente sobre los presupuestos que conlleva el efectivo "acaecer del sentido" y del correspondiente "sinsentido", sin tampoco acabar de establecer los criterios de validez desde los que se deben valorar este tipo de procesos. Sin embargo, Apel opina que este tipo de reflexiones, en vez de ayudarle a prologar y culminar sus iniciales proyectos programáticos respecto de la elaboración de una nueva metafísica, sólo sirvieron para todo lo contrario, a saber: generar la sospecha de que sus propuestas de superación, tanto de la metafísica moderna como de la clásica, podrían acabar fomentando un uso aún más alienante de los procesos de creciente independencia y autoemancipación alcanzados en estas nuevas formas de falsa "ilustración", mientras no se dispongan de unos criterios de validez que justifiquen su uso correcto en la vida práctica. ${ }^{43}$

En cualquier caso, la filosofía del "Gestelt" del último Heidegger, o la filosofía de lo "ya dado" o de lo "ya dispuesto", acabaría propiciado una segunda fase de la fenomenología donde el "acontecer" del sentido y la recreación del lenguaje se dejaría en manos de un destino que ya escapa al control individual por parte de los miembros de una comunidad, incluso a los propios investigadores que pueden conformarla. Se tendió así a confundir la historia del ser con la ya mencionada historia del lenguaje cotidiano concebido como un todo a través del tiempo, al modo como también puede suceder con la historia del mundo. Desde este punto de vista, la estructura transcendental discursiva estaría

subjetiva y la objetiva, diferencia que posibilita comprobar o justificar cuanto hemos afirmado de la cosa; en el caso de 'despejamiento' (Lichtung) -que, en tanto que 'desocultación' del sentido implica, a la vez, 'ocultación' del posible sentido -falta esa diferencia sujeto-objeto y, por tanto, falta la posibilidad de justificación inmediata, aunque el 'despejamiento' (Lichtung) abra 'ya siempre' el espacio para la posible verdad o falsedad de los juicios". (TF, I, 39, 40 pp.). Cf. Henderson, D.; Greco, J., Epistemic Evaluation. Purposeful and Epistemology, Oxford: Oxford University Press, 2016.

${ }^{43}$ A este respecto, afirma Apel: “No niego ni infravaloro la relevancia gnoseológica que posee el hecho de acentuar al 'acontecer del sentido' -que no pude manipularse [...] en todos los procesos calificados de 'productivos'- en la ciencia moderna, como 'creativos'-; pero a mi juicio, no hace falta negarla o infravalorarla, para percibir el carácter unilateral y vacilante de una filosofía [...] que cree poder superar u olvidar la metafísica moderna, fundada en la autonomía del sujeto que piensa, quiere y actúa -de igual modo que anteriormente la ontología de la 'presencia', fundada por Aristóteles-, es lícita, al menos, la sospecha de que el hombre podría jugarse la 'independencia' lograda en la 'ilustración' bajo el signo de la autonomía de la razón, en aras de una nueva 'alienación' (como dice J. P. Sartre del último Heidegger) que consiste en una nueva creencia en el destino". TF, I; 38. 39 pp.). Cf. González Arribas, B., Reduciendo la violencia. La hermenéutica nihilista de Gianni Vattimo, Madrid: Dykinson, 2016. 
ya determinada de un modo absoluto, y con ella la propia historia del ser, sin que hubiera ningún margen de actuación para el obrar libre humano. ${ }^{44}$

\section{El doble límite de la persona-núcleo en el marco de una estructura transcendental discursiva, según Polo}

Finalmente, Polo también reacciona con virulencia ante las propuestas metafísicas un tanto desconcertantes de Heidegger, pretendiendo otorgarles una orientación diferente. De hecho, Polo otorga a Heidegger el mérito de haber prolongado las propuestas de la ontológica clásica, llevando a cabo una efectiva renovación en el modo de abordar numerosas cuestiones que estaban de algún modo atascadas, volviendo a reincidir en el mismo tipo de dificultades. A este respecto, el mayor mérito que atribuye a Heidegger es haber puesto de manifiesto un conjunto de problemas que habrían permanecido latentes en el pensamiento clásico y cuya solución se daba por sobreentendida, cuando contenían un gran número de posibilidades heurísticas que en gran parte permanecían inéditas. Pero, de igual modo, también se denuncia la excesiva carga de materialismo naturalista presente en su modo de concebir la ontológica, sin dejar prácticamente espacio para la cultura y el propio desarrollo de las facultades intelectuales, a la que desde un inicio se tacha de esencialista y de haber desvirtuado a lo largo de la historia el sentido existencial otorgado en cada caso al ser. A este respecto, se considera que la gran asignatura pendiente de las propuestas heideggerianas se traduciría en el papel manipulador otorgado a la cultura, concibiendo como un enemigo al mejor aliado que habría podido tener en su pretensión de rehabilitar a una auténtica metafísica. ${ }^{45}$

\footnotetext{
${ }^{44}$ A este respecto, afirma Apel: "Con todo, la segunda fase de la fenomenología (en cierto respecto ya el último Heidegger) intentó dar una nueva respuesta que hiciera justicia a la historicidad del sentido y al aspecto creador del lenguaje. [...] La reorientación general de esta cuestión a lo largo del siglo XX corrió a cargo de la lingüística. Así como se plantea en esta la realidad del lenguaje tal y como existe para nosotros como un todo a través del tiempo, así se querrá explicar la producción literaria (y del habla humana) [...] como algo absoluto, un absoluto antes de toda explicación, como lo es el mundo en el que nos encontramos". (TF, I, 85 p.). Cf. AAVV., "Nostalgia de la comunión: la persona en la historia", Relectiones, núm. 3, Noviembre, 2016, Servicio de Publicaciones, Universidad de Navarra, 2016.

${ }^{45}$ A este respecto, afirma Polo: “Una cierta modificación del planteamiento griego es la filosofía de Heidegger, en la cual la latencia como estado se integra en el punto de partida del conocimiento. La situación del hombre alberga la latencia. [...] Con ello se amplía lo susceptible de investigación fenomenológica, ya que la latencia ingresa en el ámbito temático. Pero resulta también que la mente pierde todo valor hegemónico -en Heidegger, la cultura es un combate sin decisión posible-, y la noción de ser se carga de materialidad y obtura el destino (del ser). [...]. El hombre no es meramente un ser que objetiva, sino un ser que comunica con el fundamento. Este segundo aspecto del margen de confianza concedido a lo real es desconocido
} 
DASEIN, PERSONEIDAD, INTERSUbJETIVIDAD Y PERSONA-NÚCleO (III). LA ESTRUCTURA transcendental discursiva después de Heidegger, en Zubiri, Apel y Polo

Por su parte, Polo también retrotrae las propuestas de Heidegger acerca de Dasein a las de Hegel, como ya se analizó en la última entrega anterior. A este respecto, para ir más allá de las propuestas de la ontología clásica, Heidegger necesitaba ir más allá de la propuesta más radical de la filosofía moderna, concretamente más allá de Hegel. Además, Polo comparte a este respecto el cambio de orientación que Heidegger sugirió de las formulaciones más escépticas del proyecto programático idealista, sirviéndose para ello de la fenomenología y de la hermenéutica, a pesar de que los resultados no acabaran siendo los esperados. Se pretendió así superar la situación de perplejidad en la que, según Polo, se encontraba la filosofía moderna posterior a Descartes, especialmente en Hegel, por no poder tematizar lo que ahora se considera el núcleo central del saber, como ahora sucede con el propio ser del hombre, como pone de manifiesto el Dasein heideggeriano. ${ }^{46}$

A este respecto, Heidegger habría denunciado la dependencia que el $D a$ sein hegeliano mantiene respecto de lo absoluto, sin poder atribuírsele ya un ser por sí mismo. Se concibe el ser-ahí como una forma de ser-otro, sin otorgar al Dasein un verdadero ser por sí mismo. En Hegel, "otro" supone una diferenciación no idéntica que se concibe como la igualdad o simple repetición de "lo mismo" o del "uno", sin otorgarles en cada caso una subsistencia o ser por sí mismo. Sólo es "otro" desde el punto de vista de una "reflexión externa" respecto de los demás posibles "otros", pero en el fondo el "ser" de cada ente se identifica al de los demás, sin que exista una diferencia efectiva entre ellos. El ser y la subsistencia de cada ente serían simple manifestaciones de la presencia del absoluto hegeliano, sin poder ya establecer una diferencia entre los "entes" y el heideggeriano "ser de los entes". De este modo, el ser-ahí o Dasein de cada ente quedaría absorbido o anulado por el ser panteísta hegeliano que se predica por igual del conjunto de todos los entes. De este modo, Etwas o "lo" otro para Hegel simplemente manifiesta la imposibilidad de una duplicidad y de la consiguiente multiplicidad de supuestos, dado que todos los entes configuran una unidad unívoca donde todos los seres son lo mismo. La diferencia entre unos y otros es una simple diferencia externa de carácter relacional, pero internamente configuran un único ser que constituye una unidad indiferenciada. De este modo se consigue pensar "lo" múltiple como

por Heidegger, para el cual si el ser es principio habría de ocultarse continuamente a quien desde él se ocupe de él". (AS, 340 p.). Brosch, T; Sander, D., Handbook of Value. Perspectives from Economics, Neuroscience, Philosophy, Psychology, and Sociology, Oxford: Oxford University Press, 2016.

${ }^{46}$ A este respecto, afirma Polo: “Para ir más allá de Hegel, Heidegger busca dar razón de la perplejidad misma en la investigación acerca de lo que hemos llamado núcleo del saber. La inclusión de la perplejidad en el plano temático concreta el sujeto como existencia humana -Dasein-". (AS, 163 p.). Cf. Scruton, R., On Human Nature, Princeton (NJ): Princeton University Press, 2017. 
uno, a costa de prescindir de la multiplicad efectiva constitutiva de los entes, para reducirla a una simple multiplicidad ficticia. Se niega la posibilidad de establecer una diferencia radical última entre los entes y el respectivo absoluto hegeliano, o en su lugar, el denominado "ser de los entes" heideggeriano. En cierto modo, se genera una paradoja que ni Hegel ni Heidegger acabaron de resolver, pero que ambos afrontan desde una estructura transcendental discursiva totalmente opuesta. Para Hegel, "lo" otro subsiste como un Dasein o ser-ahi diferenciado, a pesar de constituir una repetición exactamente idéntica a "lo" anterior. Heidegger, en cambio, asigna a cada Dasein o un ser-ahí diferenciado que hace que "lo" otro no sea una simple repetición de lo anterior. Sin embargo, el establecimiento de esta separación entre los entes le exige tener que establecer una diferencia radical última intransitable entre los entes y el correspondiente "ser de los entes" que a su vez todos ellos configuran. En cambio, el ser-ahí del Dasein hegeliano no puede ser pensado al margen de la identidad que cada Dasein establece con un absoluto inalcanzable, donde el pensamiento se identifica con lo real. Incluso cuando esta dependencia es negada renace aún con más fuerza su subsistir en el absoluto, por ser la forma un tanto paradójica como el absoluto se hace presente en cada ente. Para Hegel, cada Dasein o ser-ahí es simplemente un momento de las infinitas manifestaciones del absoluto a través del lenguaje cotidiano, sin poder abarcarlo en su totalidad, pero sin poder tampoco abandonar o dejar de mantener una dependencia absoluta respecto del fundamento. ${ }^{47}$

Pero a pesar del modo tan distinto de concebir la estructura transcendental discursiva, Polo considera a Heidegger como un intento de culminación de las propuestas hegelianas de alcanzar un efectivo autoconocimiento del papel desempeñado por el Dasein en el ejercicio de dicha estructura transcendental. Heidegger concibe como un progreso el abandono que en su caso se produce de la noción de evidencia, aunque subsiste en Heidegger una actitud de permanente

\footnotetext{
${ }^{47}$ A este respecto, afirma Polo: “El ser-ahí (en Hegel) 'no es lo que es por sí mismo' (I, pág. 115). Precisamente su determinación consiste en ser otro, 'otro' es introducido como determinación según su significación, inidéntica o irreductible a la suposición de uno, es decir, a la situación anterior a la introducción. Por eso se dice enseguida que Etwas u otro son 'una y la misma cosa', para la 'reflexión exterior' o meramente comparativa, que no penetra sino que se limita a proceder mediante cambios de la atención únicamente. Cuando se hace jugar el dinamismo del pensar, se ve que 'otro' no es otro que Etwas sino en sí, 'otro de sí mismo' (I, pág. 105). [...] De este modo 'otro' verifica su noción en cerrada no duplicidad de supuestos. Es decir, en el seno de su proceso que tiende a comparecer: estricta inidentidad hegeliana. 'El otro por sí es el otro por relación a; así pues, el otro de sí mismo, el otro del otro, por lo tanto, lo que es desigual en sí, lo que se niega, lo que varía' (I, p. 106). Pero con ello se logra y verifica el pensar-lo. 'Etwas se conserva, subsiste en su ser-ahí: forma esencialmente uno consigo y no menos esencialmente no forma uno consigo' (I, p. 106). Ser-ahí sólo renace en el subsistir de su negación, no es dejado al margen de ella, inalcanzado por ella. Es así como entra en relación consigo. Lo que subsiste sin ser dejado es lo que Hegel llama momento". (AS, 237, 238 pp.).Cf. Bader, K.; Weber, K. (HG.), Alltägliche Lebensführung, Hamburg: Argument, 2016.
} 
DASEIN, PERSONEIDAD, INTERSUbJETIVIDAD Y PERSONA-NÚCleO (III). LA ESTRUCTURA transcendental discursiva después de Heidegger, en Zubiri, Apel y Polo

perplejidad, precisamente por no poder encontrar un buen sustituto a la noción de evidencia. A este respecto, Heidegger habría pretendido sustituir la noción de evidencia con la noción de autocomprensión del ser que pudiera hacer sus veces, pero tampoco esta noción resulta viable cuando el propio Dasein sólo se puede autocomprender desde un "ser de los entes" que a su vez resulta inalcanzable. El ser-ahí del Dasein sólo podría ser objeto de un proceso de comprensión correlativa a la comprensión respecto de los otros Dasein, dando lugar a un proceso al infinito en sí mismo paradójico. Pero en ningún caso se podría tipificar la perplejidad que genera el proceso de autocomprensión del Dasein, como si se tratara de investigación heurística perfectamente definida. ${ }^{48}$

De todos modos, Heidegger habría podido perfectamente superar la perplejidad que aún se hace presente en sus propuestas, de haber sido consecuente con la inicial estructura transcendental discursiva que en su caso estableció entre los entes. En efecto, si hubiera prolongado sus iniciales reflexiones sobre el fundamento como abismo (Abgrund), habría podido seguir estableciendo una relación del Dasein respecto al "ser de los entes", sin necesidad de pretender justificar la relación al fundamento mediante procedimientos meramente psicológicos o de carácter dialéctico. En su lugar, habría apreciado cómo la fenomenología y la hermenéutica remiten al Dasein a una estructura transcendental discursiva, a la que se asigna un fundamento como "abismo". Es decir, una fundamentación que exige que el hombre se autotranscienda a sí mismo para poder hacer pie en un punto de partida firme ajeno a sí mismo, dada la situación de perplejidad generalizada que ahora generan las relaciones consigo mismo. Precisamente la superación de la perplejidad por recurso al ser concebido como un abismo de profundidades insondables requiere un ejercicio muy específico de la ahora denominada libertad transcendental, cuando se comprueba que la estructura transcendental discursiva no se puede justificar a partir de uno mismo. Es decir, una vez descubierta la inesenciabilidad o ambigüedad esencial de la referencia a uno mismo, a Heidegger ya no le habría quedado otra solución que ir más allá de Hegel, tratando de delimitar la perplejidad en el ámbito específico de la autorreflexión de la existencia humana, tratando de encontrar un fundamento que se situara más allá de sí mismo. ${ }^{49}$

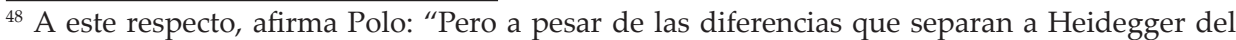
idealismo histórico, Sein und Zeit es una reedición de la pretensión idealista de autoconocimiento. El progreso, si lo hay, consiste en abandonar el ideal de evidencia. La actitud idealista, como remanente que se reduce a la perplejidad, se determina en correspondencia con la evidencia, y así la cifra de la completa incapacidad del idealismo histórico para realizar la pretensión de autoconocimiento. La perplejidad entendida como primaria situación cognoscitiva del hombre no puede ser ninguna actitud intelectual ya concretada". (AS, p. 187). Cf. Willians, B., La ética y los límites de la filosofía, Madrid: Cátedra, 2016.

${ }^{49}$ A este respecto, afirma Polo: “Una mayor agudeza en este texto de Heidegger: "Pero para poder comprenderse a sí mismo como abismo - "Abgrund" - el hombre debe transcenderse a sí mismo. Este carácter abisal del hombre no es nada que se revele en cualquier dialéctica o 
Sin embargo, Heidegger no habría proseguido el camino hacia el "abismo" o el fundamento insondable que él mismo habría descubierto. Frente a un fundamento de esta naturaleza, el hombre se encuentra ante una estructura transcendental discursiva siempre abierta a posibles profundizaciones ulteriores, sin encontrarse paralizada por la perplejidad que genera un fundamento encerrado en sí mismo. Es decir, se localiza un fundamento apropiado que da razón de la libertad que ahora se asigna a la estructura transcendental discursiva para proseguir avanzando en sus propias indagaciones, superando la situación de perplejidad paralizante en la antes se encontraba. A este respecto, el logos humano debe reconocer su carácter creado o hecho a partir de la nada, así como su dependencia respecto de un logos increado que a su vez se afirma como fundamento de las ilimitadas posibilidades de profundización asignadas a la estructura transcendental discursiva propia del logos creado humano. ${ }^{50}$

En este contexto, Dios aparece como el fundamento abisal nunca suficientemente profundizado mediante el que se legitima la libertad creada del logos humano. De este modo, el ser humano se encuentra inserto en una estructura transcendental discursiva que no se le impone como un todo ya hecho y configurado, sino que se encuentra abierto a ilimitadas posibilidades de discernimiento y deliberación nunca suficientemente investigadas. A este respecto, las posibilidades de desarrollo heurístico tienen un significado eminentemente personal en cuanto ponen de manifiesto las ilimitadas posibilidades de desarrollo de la persona en el ámbito intelectual Eso sí, se trata de una posibilidad de desarrollo de carácter regulativo por cuanto tratan de reflejar el orden de las ideas existente en el logos increado divino, sin pretender asignar la constitución de los entes creados al ejercicio efectivo de su libertad intelectual. ${ }^{51}$

análisis psicológico. La eclosión del abismo en la transcendencia fundadora es más bien, el movimiento primario que efectúa, con nosotros, la libertad ... De este modo, la inesencialidad del fundamento sólo es superada por la existencia fáctica; pero esta nunca deja al margen - beseitigt -" (Von Wesen des Grundes; Frankfurt a. M., 1949, pags. 49 y ss. El subrayado es mío). Para ir más allá de Hegel, Heidegger busca (...) la inclusión de la perplejidad en el plano temático concreto el sujeto como existencia humana-Dasein-".(AS, 162-163 pp.). Cf. MARquier, A.; La libertad de ser. El camino hacia la plenitud, Barcelona: Luciérnaga, 2000 (1) $) 2017$.

50 A este respecto, afirma Polo: "La diferencia entre el logos creado y el Logos increado está en que el primero es naturaleza y el segundo persona. Como naturaleza, el logos depende; sólo así es novedad y no simple rememoración o reunión. El olvido de la dependencia da lugar a la noción de absoluto. El absoluto es la versión naturalista de la unidad infinita (...) La distinción entre la persona y la naturaleza racional puede caer en el olvido por la virtualidad de esta última. En cuanto que el logos depende en exclusiva de la persona, es independiente de todo lo demás. (...) Así pues, para ampliar la consideración del logos es menester no olvidar la consideración de la persona, es decir, excluir toda otra dependencia". (AS, 79, 81 y 84 pp.). Cf. Perler, D.; The Faculties: A history, Oxford: Oxford University Press, 2015.

51 A este respecto, afirma Polo: “Dios, identidad originaria, otorga la libertad creándola. La distinción entre núcleo y logos es propia de la libertad creada. (...) Debido a ello, el estudio del intelecto ha de atender, ante todo, a su significación personal. (...) Sólo porque depende de la libertad creada, es decir, otorgada, el conocimiento intelectual es regulativo y no depende de 
DASEIN, PERSONEIDAD, INTERSUbJETIVIDAD Y PERSONA-NÚCleO (III). LA ESTRUCTURA transcendental discursiva después de Heidegger, en Zubiri, Apel y Polo

En este contexto, el logos creado humano se concibe como una ilimitada apertura a la verdad inescrutable del logos increado divino, susceptible de una permanente novedad unificante que le puede obligar a reestructurar todos los conocimientos a los que hasta entonces se les otorgaba un valor definitivo. Su pretensión fundamental es "hacer suyas" el conjunto de las verdades creadas referidas a la naturaleza, así como las distintas dimensiones de conocimiento, tratando de justificar racionalmente el orden natural existente entre las cosas. Precisamente el núcleo del saber consiste en un ejercicio de la libertad transcendental mediante la que el logos creado humano trata de reflejar el conjunto de verdades contenidas en el logos increado divino. A este respecto, el logos humano trata de hacer suyas las verdades que ya han sido descubiertas e incorporadas al núcleo del saber. En este sentido, el núcleo del saber es susceptible de una creciente ampliación que a su vez redunda en un creciente enriquecimiento intelectual de la persona. Sin embargo, no hay que confundir el orden ser-saber que compete a la persona, respecto de despliegue analítico de las causas que pertenece al orden del ser y que propiamente compete al ser principal. ${ }^{52}$

A este respecto, Polo separa claramente la persona respecto del núcleo del saber. La persona pertenece al orden del ser, y el logos creado depende a su vez de la persona, y en ese sentido tiene un carácter personal. En cambio, el logos humano pertenece al orden del conocer, sin constituir una unidad suprema, sino en todo caso dependiente y unificante, en la medida que trata a su vez de reflejar la permanente novedad inescrutable del logos increado divino. Pero el logos humano siempre mantiene una dependencia respecto de la persona, como de algún modo pretendía reflejar la noción clásica de persona: supuesto de naturaleza racional, para contraponerla a la noción de persona divina. ${ }^{53}$

la libertad en cuanto propiedad" (AS, 142 pp.). Cf. Murillo, I. (ed.); Pensar y conocer a Dios en el siglo XXI, Colección Jornadas 10, Ediciones Diálogo Filosófico, Madrid, 2016.

${ }^{52}$ A este respecto, afirma Polo: "El logos humano es, ante todo, una novedad unificante; y, por lo tanto, no es una mera reunión, ni una reiteración, sino un hacer-suyas las distintas dimensiones del conocimiento. Con la expresión 'hacer suyas' se señala, ante todo, la referencia al núcleo del saber. El núcleo se ha caracterizado como la libertad transcendental. El logos es la novedad que dispone o hace-suyo, es decir, la pura dependencia respecto del núcleo. Con esta dependencia, se reconoce inicialmente el carácter personal del núcleo del saber. El logos depende exclusivamente del núcleo y de este modo se distingue del despliegue analítico de las causas, que depende del ser principal". (AS, 78 p.). Cf. Gómez-Heras, L. M. Gä; Martín Gómez, M. (Eds.), Comprender e interpretar. La recepción de la filosofía hermenéutica en la España democrática (1960-2010), Salamanca: Instituto Humanidades, Universidad Rey Juan Carlos, 2015.

${ }^{53}$ A este respecto, afirma Polo: "El logos humano no es unidad suprema, sino unidad dependiente y unificante, que hace suyas dimensiones distintas. La dependencia, como decíamos, es su referencia a la persona. A ello alude, siquiera veladamente, la noción clásica de persona: supuesto de naturaleza racional. Esta noción sólo puede aplicarse con rigor a la persona creada". (AS, 79 p.). Cf. Evnine, S. J., Making Objects and Events. A hylemorphic Theory of Artifacts, Actions, and Organisms, Oxford University Press, Oxford, 2016. 
El núcleo del saber no constituye el principio transcendental de la estructura discursiva del conocimiento humano, sino simplemente un principio unificante y dependiente en todo momento del principio transcendental del ser. A este respecto, también conviene distinguir el orden del conocer y el orden del ser, ordenándose el primero al segundo y no a la inversa. En este sentido, la estructura transcendental discursiva mantiene una dependencia respecto de la estructura transcendental entitativa, que aún no se ha analizado. En este contexto el orden del conocimiento discusivo trata de encauzar y explicitar el orden sobreentendido que se encuentra implícito en el orden del ser. En este sentido, el orden del conocimiento nunca refleja de una forma exhaustiva el orden ser, ni tiene tampoco un punto de partida fijo, sino que simplemente pretende aproximarse sucesivamente lo más posible, aunque siempre subsista una distancia entre ellos. Lo decisivo en cualquier caso es la prioridad del orden del ser sobre el del conocer, dado que sin ejercicio de la principialidad del ser tampoco tendría sentido la existencia de una estructura transcendental del saber dicuresivo. ${ }^{54}$

En este contexto, la persona se sitúa en el orden del tener o del disponer, aunque no por ello pueda disponer del logos a su antojo, sino que sólo puede disponer según las reglas de su específica naturaleza. A este respecto, la persona tiende a disponer de las cosas en la medida que las hace suyas con ayuda de la inteligencia. De este modo, la persona se apropia y hace suyos los objetos que conoce, en la medida en que unifica las distintas dimensiones de los entes que a su vez posee, ejerciendo un dominio racional en el consiguiente uso que hace de ellos. En este sentido, las cosas están a disposición de la persona en la medida que puede conocerlas y reconocerlas como suyas, por estar reguladas mediante una estructura transcendental discursiva de la que forman parte tanto las personas como las cosas..$^{55}$

\footnotetext{
${ }^{54}$ A este respecto, afirma Polo: "El núcleo del saber no es el principio transcendental. Justamente conviene llamar principio a aquello de que primariamente se distingue el núcleo del saber en el plano transcendental. El principio transcendental es el ser. [...] El conocimiento del ser es la función operativa del conocimiento. El conocimiento operativo se encauza, y justamente como explicitación, en orden al ser. [...] El conocimiento operativo, encauzado como explicitación, es decir, como prosecución en orden a su propio implícito, obedece a la persistencia del ser. De esta manera, su carácter de secuencia no es una sucesión lineal indefinida, ni tiene un punto de partida dado y fijo, sino que se 'acerca' al ser en cuanto que respeta la persistencia de su principialidad”. (AS, 54 p.). Cf. VANNEY, C.; Lombardi, O. (Ed.), Fronteras del determinismo: Filosofía y Ciencia en diálogo, Madrid: Editorial Biblioteca Nueva, 2015, 237 pp.

${ }^{55}$ A este respecto, afirma Polo: "En cuanto que dependiente en exclusiva, el tener es el disponer. El logos depende de la persona, no porque la persona disponga de él, sino porque dispone según él. La naturaleza de la persona es la unificación dependiente de una posesión nuclear que dispone según ella, y por lo tanto, el disponer mismo, el hacer-suyas. Hacer-suyas es el carácter de según con que las dimensiones unificadas están a disposición. Respecto de todas las dimensiones con excepción del núcleo del saber, hacer-suyas tiene valor cognoscitivo". (AS, 80 p.). Cf. HügLI, A., Von der Schwierigkeit, vernünftig zu sein, Basel: Schwabe, 2016.
} 
DASEIN, PERSONEIDAD, INTERSUbJETIVIDAD Y PERSONA-NÚCleO (III). LA ESTRUCTURA transcendental discursiva después de Heidegger, en Zubiri, Apel y Polo

La estructura transcendental discursiva hace posible que la persona disponga de la universalidad de los entes en la medida que se apropia de su modo de ser haciéndolos suyos con ayuda de la inteligencia. La apertura de la inteligencia a la totalidad de ser comporta que los entes quedan a disposición de la persona, en la medida que es capaz de descubrir el orden inteligible por el que se regulan. Además, posteriormente, a este orden natural se le puede sumar un segundo orden de carácter técnico o cultural, en la medida que se le sobreponen otros fines y regulaciones generadas por el propio hombre. Sin embargo, todas estas formas de posesión o de apropiación superpuesta o derivada presuponen la previa relación de tenencia natural o espontánea, que es esencial para el hombre. El hombre no sólo dispone de una riqueza ontológica ilimitada por su capacidad de apertura a todos los entes, sino que además tiene una capacidad de disponer y hacer suyas a todas las cosas por ser el mejor modo como puede acabar respetando su correspondiente naturaleza. En este sentido los entes-útiles son para el hombree, como también había afirmado Heidegger, pero a su vez el hombre debe ejercer un dominio respetuoso sobre las entes, de modo que formen parte y contribuyan a enriquecer los distintos proyectos programáticos de su libertad transcendental, sin dejarlos al margen. ${ }^{56}$

Heidegger también hubiera podido seguir esta línea de argumentación al tratar de justificar la peculiar estructura transcendental discursiva que hace posible la comprensión del ser. Sin embargo, según Polo, el último Heidegger habría dado un giro de naturaleza muy distinta en su filosofía del "Gestell", del armazón, de lo ya dado o dispuesto, o de la conexión, como ahora se prefiere denominar. En efecto, según Polo, ya en Ser y tiempo Heidegger habría tratado de fundamentar la comprensión de los entes y del "ser de los entes" en nombre de la libertad transcendental asignada al Dasein. De este modo Heidegger habría pretendido sustituir aquella perplejidad inicial de fondo que generaron sus propuestas iniciales mediante una doble dirección, a saber: por un lado, admitir el posible sentido que el "Dasein" puede otorgar a una estructura transcendental ontológica mediante un salto hacia delante que ahora se legitimaría en nombre precisamente de aquella libertad transcendental y del correspondiente destino histórico, sin tampoco remitirse a un

${ }^{56}$ A este respecto, afirma Polo: "Recapitulemos: Hacer-suyas comporta dependencia exclusiva respecto de la persona. La dependencia exclusiva ha de interpretarse como disponer. El hombre tiene en cuanto que dispone. Por lo tanto, el tener es en él estricto y no se reduce a lo tenido; no es simple adscripción o situación derivada, sino la unidad según la cual se tiene. Tal unidad es esencial para el hombre. La esencia del hombre no es meramente, riqueza ontológica, sino, lo que más, el tener como sentido: el saber hacer. [...] El hombre no tiene formalidades, sino que 'formaliza' según el tener. [...] Disponer no es tener lo tenido, sino la dependencia, en modo alguno causal, en que la libertad transcendental se analiza según el tener como unificación". (AS, 82, 83 pp.). Cf. MageeE, B.; Ultimate Questions, Princeton: Princeton University Press, 2016. 
abismo de profundidades inaccesibles , como ocurría en la metafísica clásica; y, por otro lado, la proyección sobre los entes de un tipo peculiar de interconexión recíproca fundada a su vez en el "ser de los entes", a pesar de saber de antemano de la imposibilidad de superar la diferencia radical última que se establece entre ellos..$^{57}$

\section{Conclusión: ¿Puede la libertad transcendental fundamentar la estructura entitativa de los seres?}

Zubiri, Apel y Polo rechazaron las prolongaciones sugeridas por el último Heidegger. Sin embargo, en todos los casos dejaron una cuestión abierta que de momento tampoco se ha considerado. ¿Hasta qué punto la estructura transcendental discursiva ahora analizada no sólo requiere de la existencia de una libertad transcendental que haga posible dicho saber discursivo, sino también de una estructura entitativa que hiciera posible llevar a cabo las discriminaciones y deliberaciones que el ejercicio de dicha libertad exige? Evidentemente se trata de una cuestión de enorme interés, pero muy compleja, que deberá ser analizado en otro momento. ${ }^{58}$

${ }^{57}$ A este respecto, afirma Polo: “La conexión -'Gestell'- de hombre y ser exige la eliminación de este doble estatismo (de la filosofía clásica). Como no propio del objeto, el sentido de ser es el arrancarse en salto desde la perplejidad de fondo. El salto no es dialéctico, sino más bien proyectivo, es decir, no referible al abismo como estática negación de sentido". (AS, 189 pp.). Cf. Priest, G., Uno. Una investigación sobre la unidad de la realidad y de sus partes, Barcelona: Alpha Decay, 2016.

${ }^{58}$ OrTiz de Landázuri, C.; Dasein, personeidad, intersubjetividad y persona-núcleo (IV). La estructura transcendental entitativa después de Heidegger, en ZubIRI, APEL Y Polo, sin publicar. 